\title{
TARGET VALUE DESIGN APLICADO AO PROJETO E MODELAGEM DE ESTABELECIMENTOS ASSISTENCIAIS DE SAÚDE: UMA EXPERIÊNCIA DIDÁTICA AVANÇADA
}

\section{TARGET VALUE DESIGN APLICADO AL PROYECTO Y MODELADO DE ESTABLECIMIENTOS ASISTENCIAL DE SALUD: UNA EXPERIENCIA DIDÁCTICA AVANZADA}

\section{TARGET VALUE DESIGN APPLIED TO THE DESIGN AND MODELING OF HEALTH CARE}

ESTABLISHMENTS: AN ADVANCED DIDACTIC EXPERIENCE

\section{MORAIS, MARCELO DE}

Doutor, pós-doutorando IAU-USP.E-mail: arqmmorais@gmail.com

\section{FABRÍCIO, MÁRCIO MINTO}

Doutor, Professor associado do Instituto de Arquitetura e Urbanismo de São Carlos da Universidade de São Paulo. E-mail: marcio@sc.usp.br

\section{RUSCHEL, REGINA COELI}

Doutora, Faculdade de Engenharia Civil, Arquitetura e Urbanismo da Universidade Estadual de Campinas. E-mail: ruschel@g.unicamp.br

\section{RESUMO}

$\mathrm{O}$ desenvolvimento de projetos de Estabelecimentos Assistenciais de Saúde (EAS) devem atender contextos relacionados à qualidade e operacionalidade da edificação, além de atender à percepção de valor dos usuários. Neste contexto o uso do Target Value Design (TVD) e da tecnologia BIM tem apresentado bons resultados no desenvolvimento de projetos na área hospitalar nos EUA, tais práticas têm como característica o estímulo à criatividade e à produção de soluções otimizadas em custo e valor, aumentando a eficiência do processo. Observa-se que atualmente a necessidade de desenvolvimento de métodos e instrumentos para esse contexto, adaptados à realidade brasileira, e que possam ser disseminados em experiências didáticas de projeto. 0 problema desta pesquisa consistiu em estudar instrumentos e métodos de aplicação conjunta do TVD e BIM no ensino e no processo de projeto de EAS. A partir da adaptação de método e ferramentas desenvolvidas em Morais (2016) para o contexto específico de projeto de EAS, foi proposto uma experiência didática reflexão crítica e projeto de Unidade Básica de Saúde (UBS). Os resultados da experiência didática realizada demonstraram a potencialidade do uso do BIM e do TVD no desenvolvimento do projeto da UBS, observou-se ainda a preocupação quanto ao atendimento às necessidades dos usuários deste tipo de equipamento.

PALAVRAS-CHAVE: Target Value Design; modelagem da informação da construção; ensino de projeto.

\section{RESUMEN}

El desarrollo de proyectos de Establecimientos Asistenciales de Salud (EAS) deben atender contextos relacionados a la calidad y operacionalidad de la edificación, además de atender a la percepción de valor de los usuarios. En este contexto el uso del Target Value Design (TVD) y de la tecnología BIM ha presentado buenos resultados en el desarrollo de proyectos en el área hospitalaria en los Estados Unidos, tales prácticas tienen como característica el estímulo a la creatividad ya la producción de soluciones optimizadas en costo y valor, aumentando la eficiencia del proceso. Se observa que actualmente la necesidad de desarrollar métodos e instrumentos para ese contexto, adaptados a la realidad brasileña, y que puedan ser diseminados en experiencias didácticas de proyecto. El problema de esta investigación consistió en estudiar instrumentos y métodos de aplicación conjunta de TVD y BIM en la enseñanza y en el proceso de proyecto de EAS. A partir de la adaptación de métodos y herramientas desarrolladas en Morais (2016) para el contexto específico de proyecto de EAS, se propuso una experiencia didáctica reflexión crítica y proyecto de Unidad Básica de Salud (UBS). Los resultados de la experiencia didáctica realizada demostraron la potencialidad del uso del BIM y del TVD en el desarrollo del proyecto de la UBS, se observó la preocupación en cuanto a la atención a las necesidades de los usuarios de este tipo de equipo.

PALABRAS CLAVES: costeo objetivo; modelado de la información de la construcción; enseñanza de proyecto.

\section{ABSTRACT}

he development of Health Care Facilities projects should address contexts related to the quality and operation of the building, in addition to attending users' perception of value. In this context, the use of Target Value Design (TVD) and BIM technology has presented good results in the development of projects in the hospital area in the USA, such practices have as a stimulus to creativity and the production of solutions optimized in cost and value, increasing the efficiency of the process. It is observed that currently the need to develop methods and instruments for this context, adapted to the Brazilian reality, and that can be disseminated in didactic project 
experiences. The problem of this research was to study instruments and methods of joint application of TVD and BIM in teaching and in the Health Care Facilities design process. From the adaptation of the method and tools developed in Morais (2016) to the specific context of Health Care Facilities project, a critical reflection didactic experience and a Basic Health Unit project was proposed. The results of the didactic experience demonstrated the potential of the use of BIM and TVD in the development of the Basic Health Unit project. it was also observed the concern regarding the attendance to the needs of the users of this type of equipment. KEYWORDS: Target Value Design; BIM; design teaching.

\section{INTRODUÇÃO}

A presente pesquisa tem como motivação a constatação de que há um grande déficit dos serviços de atenção à saúde, principalmente na esfera pública, caracterizado ainda pela precariedade das condições de trabalho de assistência médica, devido a estrutura física dos edifícios e sua necessidade constante de adequações, adaptando ao uso de novas tecnologias, melhorando a humanização do atendimento, e se adaptando as novas diretrizes e regulamentações estabelecidas pela Agência Nacional de Vigilância Sanitária (ANVISA) (CUNHA, 2004; BITENCOURT, 2006; GOES, 2004).

Para a organização dos Estabelecimentos Assistenciais de Saúde (EAS) é indispensável a interação entre todas as atividades da instituição de saúde, pois há relações de diferentes níveis de tecnologia e profissionais, aumentando a complexidade desses edifícios (GOES, 2004).

Para o Arquiteto Roberto Aflalo uma das formas de se atender a todas essas premissas e evitar problemas durante a execução desses empreendimentos, é imprescindível a compatibilização entre os projetos (arquitetura, estrutura, sistemas de instalações prediais e HVAC). O uso da Modelagem da Informação da Construção (em inglês: Building Information Modeling - BIM) vem contribuindo para o desenvolvimento de projetos na área hospitalar. Sendo possível, pelos sistemas de detecção de conflitos do software, antecipar inconsistências de projeto, que só seriam percebidas na fase de execução (GIRIBOLA, 2014).

Ballard (2008) e Eastman et al (2011) reforçam que por meio da utilização da Engenharia de Valor e do Target Value Design (TVD), apoiados em modelos de informação da construção, os ganhos podem ser consideráveis. A modelagem paramétrica da informação, as possibilidades de comunicação e a colaboração entre as equipes de projeto facilitam a tomada de decisão ainda nas suas fases iniciais de concepção, período no qual a redução dos custos pode ser mais significativa (COOPER; SLAGMULDER, 1997).

Atualmente, com a finalidade de alavancar produtividade e os lucros da construção civil, além de novas ferramentas de $\mathrm{TI}$, conceitos provenientes da indústria de manufatura (como o target costing, custeio-meta ou Target Value Design) também têm sido incorporados ao cotidiano do setor. O TVD considera como informação, já nas fases iniciais de projeto, o aumento do valor do produto de acordo com as necessidades do usuário. Ainda outra preocupação, para além das estimativas de custo da obra, seria o levantamento dos custos de produção, o que é essencial para os processos de redução de gastos (JACOMIT; GRANJA, 2011).

O TVD possui uma grande sinergia com BIM e vem sendo utilizado com sucesso no desenvolvimento de empreendimentos hospitalares nos EUA, desta forma percebe-se a necessidade de instrumentos e métodos para viabilizar e adaptar seu uso a realidade nacional (MORAIS; GRANJA; RUSCHEL, 2015).

Sendo assim, o objetivo desta pesquisa foi a adaptação de métodos e instrumentos, segundo Morais (2016), que possam subsidiar a prática integrada de projeto com TVD e BIM para à realidade brasileira e que possam ser disseminados em experiências didáticas de projeto, e no desenvolvimento de novos projetos para EAS que serão construídos na região objeto de estudo ou em contextos similares.

Para a adaptação dos métodos e instrumentos de Morais (2016), deu-se continuidade a abordagem do Design Science Research (DSR), desenvolvida anteriormente, visando a criação de novos artefatos que que apoiam o uso de TVD e BIM no contexto de projetos de edifícios da área de saúde e utilizá-los em uma disciplina de pós-graduação. Para a criação dos artefatos foi realizado um estudo de caso exploratório, que consistiu na análise do processo de desenvolvimento de edifícios de saúde da Prefeitura Municipal de Araraquara, tendo como referência para o desenvolvimento dos artefatos uma Unidade Básica de Saúde (UBS), que foi construída recentemente no município. Já a aplicação prática dos artefatos ocorreu em uma disciplina de pósgraduação em Arquitetura e Urbanismo oferecida pelo Programa de Pós-Graduação do Instituto de Arquitetura e Urbanismo da Universidade de São Paulo (IAU-USP), durante o segundo semestre de 2017.

Desta forma o artigo além relatar a experiência didática em uma disciplina de pós-graduação em arquitetura, descreve os Instrumentos e o "Método para utilização de BIM apoiando Target Value Design na concepção de Estabelecimentos Assistenciais de Saúde1", que subsidiaram as atividades ao longo da disciplina de pósgraduação e do Workshop de projeto. 


\section{DOMÍNIO DO PROBLEMA: USO DE TVD E BIM EM PROJETOS DE ESTABELECIMENTOS DE ASSISTÊNCIA À SAÚDE}

Para projetar a arquitetura de Estabelecimentos Assistenciais de Saúde (EAS) é necessário levar em consideração uma série de normas e portarias da Agência Nacional de Vigilância Sanitária (ANVISA) peculiares a cada ambiente de atendimento médico. Assim como os requisitos da Resolução de Diretoria Colegiada no 50 de 2002 (RDC 50/2002), que dispõe sobre o regulamento técnico para planejamento, programação, elaboração e avaliação de projetos físicos de estabelecimentos assistenciais de saúde (ANVISA, 2002; CONSELHO FEDERAL DE MEDICINA, 2011; GIRIBOLA, 2014).

Segundo Bross (2013) ao longo do processo e construção de edifícios da área da saúde um dos problemas verificados é a baixa qualidade na informação técnica das planilhas orçamentárias, o que acaba recorrendo em custos que oneram as previsões iniciais.

Pensando em amenizar tais situações o Bross (2013) propõe a criação de estruturas gerencias que possam avaliar de forma constante os processos e o espaço físico dos edifícios, propondo estruturas gerenciais de melhoria contínua, baseadas em experiências já realizadas, contendo informações de custos operacionais e de construção, permitindo sua replicabilidade (através de plataformas tecnológicas adequadas) no desenvolvimento de novos projetos, visando a utilização de recursos provenientes do setor público ou privados, que na maioria das vezes são escassos e devem ser utilizados imediatamente.

Para Bitencourt e Costeira (2014) os edifícios hospitalares devem sofrer atualizações constantes para se adequar as novas tecnologias e normativas de saúde e segurança, devendo assim a todo momento, reconstruir-se, expandir e se reequipar constantemente. As abordagens nesse contexto devem englobar aspectos multidisciplinares, envolvendo questões ligadas ao conforto ambiental, as demandas do paciente, envolvendo para isso conceitos e ferramentas de avaliação do ambiente de saúde, projeto e planejamento que darão subsídios para construção e o gerenciamento operacional do edifício (BITENCOURT, COSTEIRA; 2014).

Como formas de contenção de custos nos empreendimentos de construção, novas abordagens de contratação como Integrated Project Delivery (IPD) e, especificamente na construção de EAS, o Integrated Form of Agreement for Lean Project Delivery (IFoA) estão sendo adotadas, assim como novos processos de desenvolvimento de projeto que passam a adotar Lean-Integrated Project Delivery (Lean-IPD), TVD e BIM (TIWARI et al., 2009; KHEMLANI, 2009; ALARCON, CHRISTIAN, TOMMELEIN, 2011; EASTMAN et al., 2011; LOSTUVALI, ALVES, MODRICH, 2012).

O TVD vem sendo cada vez mais usado nos processos Lean-IPD na construção de Healthecare no EUA, as iniciativas inovadoras implementadas no SUTTER MEDICAL CENTER CASTRO VALLEY (SMCCV), na Califórnia, impulsionaram o setor para a utilização de práticas colaborativas, gerenciamento de valor e o uso de modelos BIM no desenvolvimento de novos projetos (RYBKOWSKI et al., 2016). Devido à necessidade de adaptação de vários hospitais, com as adequações necessárias para o grande desenvolvimento tecnológico do setor e das normas CA SB 1953, referente a abalos sísmicos do estado da Califórnia, após diversas aplicações nessa área, o TVD vem se aperfeiçoando (KHANZODE; FISCHER; REED, 2013).

O TVD é um método que teve origem na indústria de manufatura sendo uma adaptação do target costing ou custeio-meta, para o desenvolvimento de produtos da construção civil, que garante ao cliente a entrega de valor, levando-se em consideração as restrições orçamentárias, (BALLARD, 2008). O TVD engloba conceitos relacionados a definições de custo-meta, ambientes colaborativos, proativos e o uso de modelos da informação da construção que apoiam a tomada de decisão ainda nas fases inicias de projeto (MACOMBER et al., 2007).

A integração entre BIM, TVD apresenta resultados positivos e demonstra como o novo processo de gerenciamento combinando as duas áreas pode proporcionar benefícios e economia de recursos na execução do empreendimento (SACKS et al., 2010).

Apesar da demanda corrente de ruptura com os processos tradicionais de entrega de projeto, uma das dificuldades encontradas é implementação prática do TVD por equipes ainda inexperientes no trabalho com ferramentas de engenharia de valor e práticas colaborativas (RYBKOWSKI et al., 2016). Pensando em sanar tais dificuldades a pesquisa propõe o desenvolvimento de métodos e ferramental para utilização de TVD e BIM em práticas colaborativas de projeto através de uma experiência didática realizada em uma disciplina de pós-graduação. 


\section{OBJETIVO E MÉTODOS}

O objetivo deste artigo é evidenciar a potencialidade do uso de ferramentas que permitem a Modelagem da Informação da Construção (BIM) no auxílio à adoção do Target Value Design (TVD), no processo de desenvolvimento de EAS, tendo como foco a orçamentação e considerando-se os custos básicos reais do setor. Buscou-se, também, a implementação de métodos e processos participativos que envolvam tais conceitos auxiliando as etapas de concepção, focando características de tipologia desses edifícios e o desenvolvimento de procedimentos didáticos avançados (nível de pós-Graduação) para disseminação destes conhecimentos.

Para a execução da pesquisa exploratória foram utilizadas fontes bibliográficas (livros, artigos) que trabalham questões teóricas e práticas em relação à problemática abordada; utilizamos, também, fontes documentais, tais como plantas e projetos de UBS já implantados no Brasil, especialmente na região da prefeitura estudada e projetos padrões de UBS disponibilizados pelo Ministério da Saúde. Como fundamentação teórica deste trabalho foi realizada uma revisão da literatura sobre aplicações do BIM e do TVD em projetos de edifícios de assistência à saúde.

Como estratégia de pesquisa, adotou-se a abordagem do Design Science Research (DSR) a que é definida por Lukka (2003), March e Smith (1995) como um procedimento de pesquisa para a produção de Instrumentos (artefatos), destinados a resolver problemas enfrentados no mundo real, contribuindo assim para 0 desenvolvimento teórico e prático no contexto da área em que ela será aplicada. A utilização do DSR teve como finalidade estabelecer a criação de artefatos que possam contribuir de forma prática para auxiliar na utilização do BIM no desenvolvimento de projetos de edifícios da área de saúde, com apoiando de métodos e ferramentas de TVD adaptados de Morais (2016).

A pesquisa e a experimentação didática foram estruturadas conforme ilustra a figura 1.

Figura 1: Atividades Didáticas e de Pesquisa

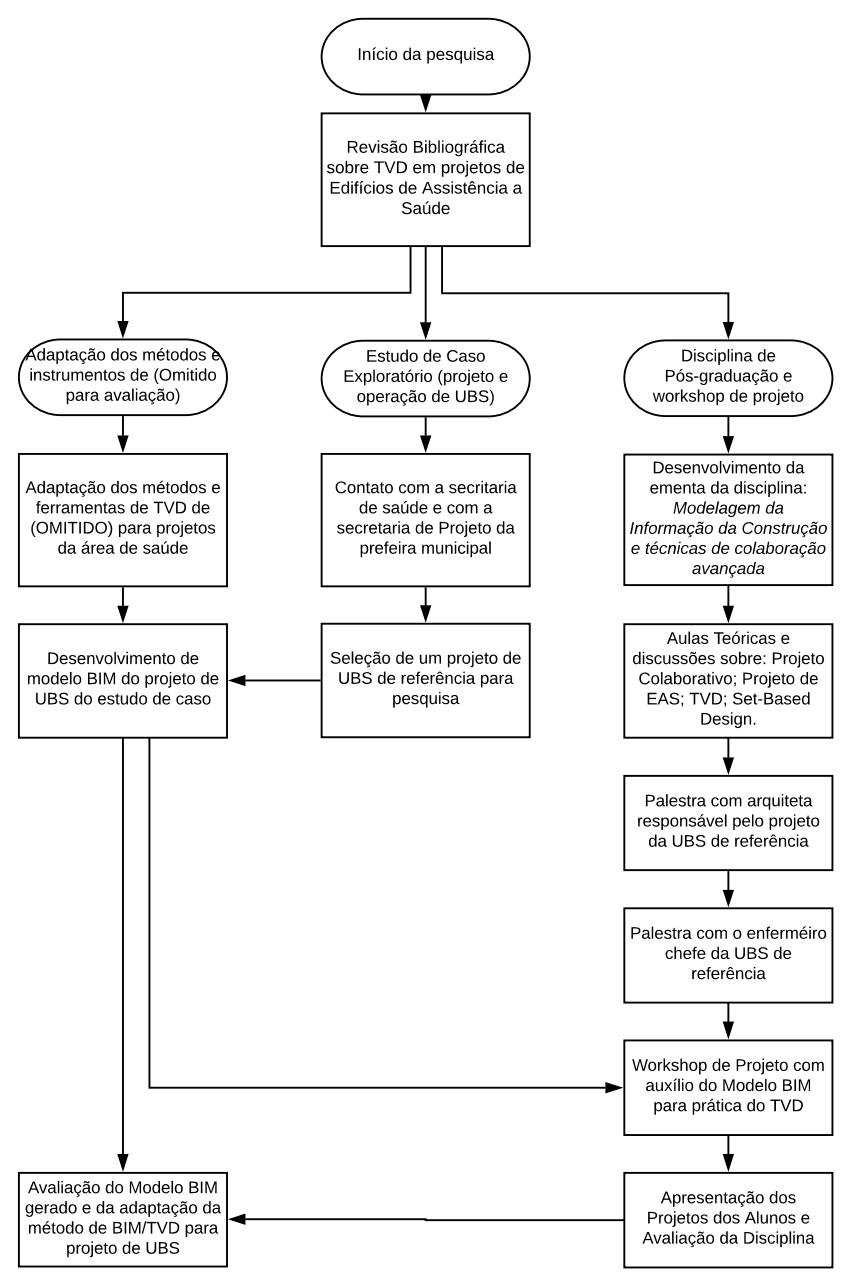

Fonte: Autores (2017) 
A primeira atividade da pesquisa foi revisar a teoria e os relatos de caso sobre emprego do BIM e do TVD no projeto de EAS. Também foram sistematizadas referências projetuais de UBS, através de fontes documentais, tais como plantas e projetos de UBS já implantados no Brasil, também foram analisados os projetos padrões de UBS disponibilizados pelo Ministério da Saúde em seu site e o projeto específico da UBS do estudo de caso exploratório.

Foi realizado um estudo de caso exploratório junto aos órgãos de projeto e secretaria da saúde da Prefeitura Municipal de Araraquara, estudada para caracterizar o processo real de desenvolvimento de UBS no município. Este estudo contou entrevista junto a profissionais de projeto de arquitetura da prefeitura, particularmente com a Arquiteta responsável pelo projeto da UBS selecionada como padrão inicial para o exercício de projeto, profissionais responsáveis pela orçamentação da UBS estudada e usuários da edificação, na pessoa do Enfermeiro Chefe da UBS estudada. Também foi realizada uma visita ao edifício da UBS utilizada no estudo.

Com base nos insumos da revisão bibliográfica e estudo exploratório foi proposto o exercício didático de aplicação do TVD para edifícios de saúde e foi construído um modelo BIM de referência da UBS estudada, inclusive com dados reais de custos da obra.

Como forma de testar e aprimorar o artefato e de difundir os conceitos e método estudados, foi conduzida a disciplina de pós-graduação Tópicos especiais: Modelagem da Informação da Construção e técnicas de colaboração avançada (IAU-5817), oferecida no programa Pós-Graduação do Instituto de Arquitetura e Urbanismo da Universidade de São Paulo (IAU-USP) no segundo semestre de 2017.

\section{DESENVOLVIMENTO DE PROCESSO PARA ADOÇÃO DO BIM APOIANDO TVD}

\section{Estudo de caso Exploratório}

Realizou-se uma visita técnica em junho e julho de 2017 à Prefeitura Municipal de Araraquara (PMA), uma cidade de médio porte do interior de São Paulo, buscando maiores informações sobre o processo de desenvolvimento dos projetos relacionados aos EAS do município. Verificou-se assim, através de entrevistas e reuniões junto às Secretaria de Obras, Secretaria de Desenvolvimento Urbano e Secretaria de Saúde, quais foram os procedimentos adotados durante o desenvolvimento real das Unidades Básicas de Saúde (UBS), construídas recentemente no município, e quais diretrizes poderiam ser aplicadas para o desenvolvimento e implementação de ferramentas computacionais que apoiassem o processo, e relacionadas ao referencial teórico da pesquisa.

Observou-se no processo de projeto da PMA estudada há pouca interação entre as secretarias envolvidas em um projeto de EAS, o processo é caracterizado pela sua linearidade e por ser baseado apenas em desenhos bidimensionais, realizados em sistemas $C A D$, o que gera retrabalhos e aumenta a possibilidade de erros. A orçamentação ocorre nas etapas finais do processo, quando praticamente o projeto já está em fase de detalhamento, prejudicando o acesso às informações de custo nas fases iniciais de projeto.

Uma das maiores dificuldades relatadas pelos agentes da PMA (arquitetos, enfermeiros e engenheiros) é a participação conjunta das equipes ao longo do processo, ela acaba sendo pontual e, na maioria das vezes, não há regras e protocolos, que irão incentivar a interação e regrar o processo de projeto realizado. As interações acabam ocorrendo nas etapas finais do projeto e da orçamentação, dificultando uma reflexão e discussão apropriada, relacionada às diretrizes e necessidades dos usuários (Figura 2). 
Figura 2: Representação de processo de projeto realizado pela PMA.

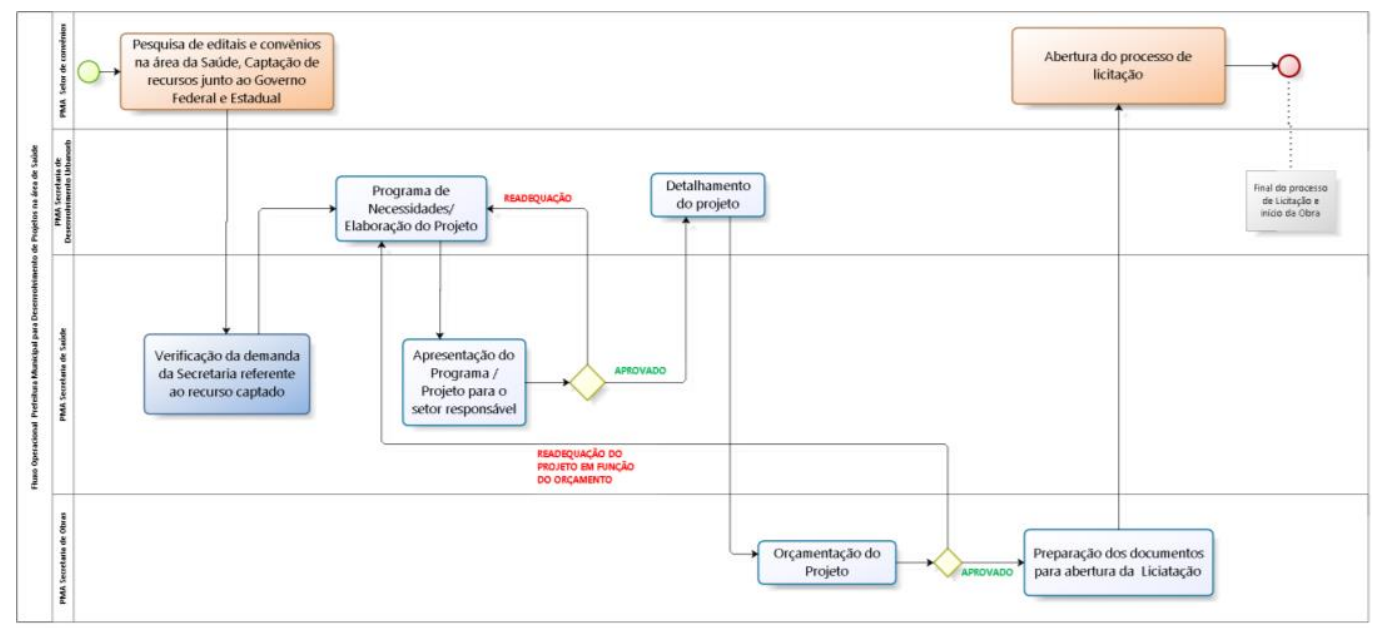

Fonte: Autores (2017)

\section{Modelo paramétrico de apoio ao Target Value Design}

Pensando nas dificuldades levantadas junto a Prefeitura de Araraquara, foi adaptado um "Método para utilização de BIM apoiando Target Value Design na concepção de Estabelecimentos Assistenciais de Saúde", (Figura 3). A proposta tem como principal característica inserir ferramental BIM e ferramentas de gerenciamento de valor ao longo do processo de desenvolvimento de projetos da PMA, e para que isso ocorra é essencial o trabalho colaborativo entre as equipes das Secretarias através de reuniões e Workshops de trabalho.

O método proposto tem como finalidade incentivar o trabalho colaborativo entre os agentes envolvidos em um projeto de EAS, tomando-se como referência a PM estudada. Para isso, adotou-se o Business Process Model and Notation (BPMN) ou "mapa de processo", que consiste em uma notação padrão que representa processos de negócios por meio de diagramas. A representação do método em mapa de processo foi utilizada devido à descrição lógica dos passos do trabalho a ser realizado, organizando o fluxo entre as secretarias, o que facilita a aplicação do método teórico proposto e torna clara e fácil a compreensão do todo e das atividades que serão realizadas por cada participante, através da sua notação gráfica.

Figura 3: proposta de um novo processo de projeto inserindo BIM e TVD na prefeitura estudada.

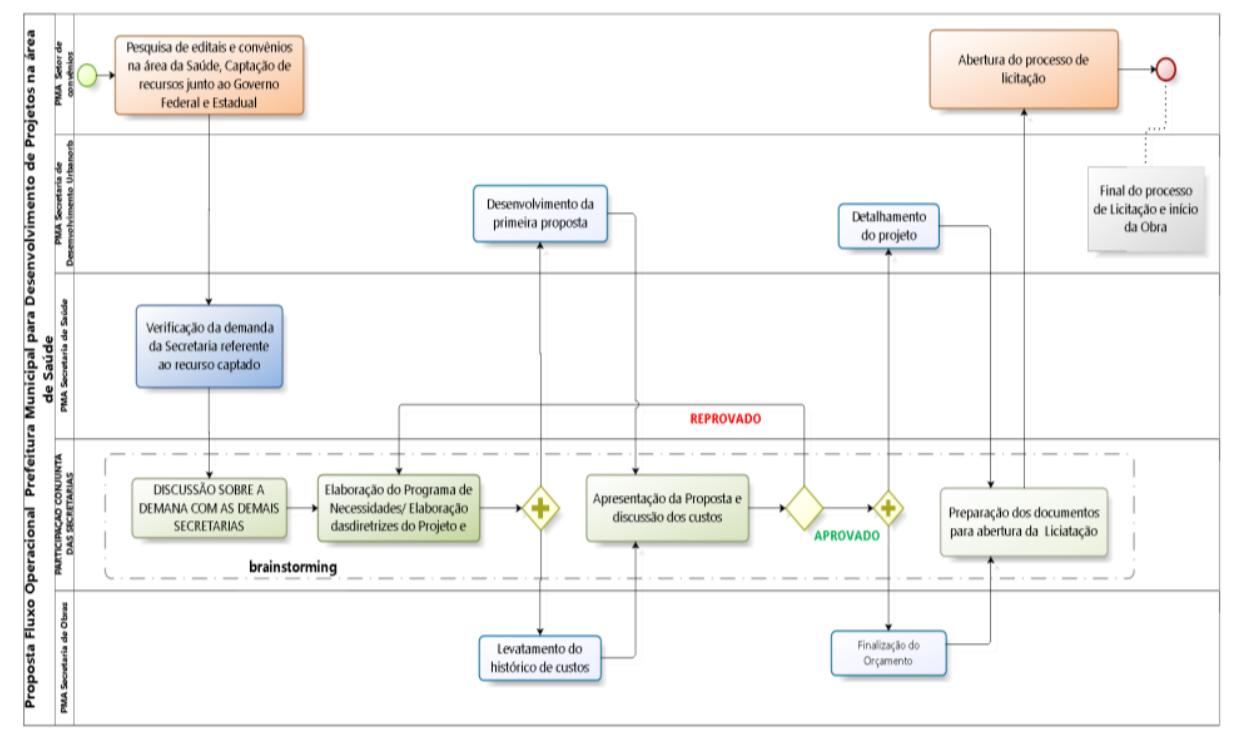


A proposta idealizada na pesquisa segue os princípios da abordagem do TVD com ênfase na entrega de valor ao cliente, no caso os usuários, enfermeiros e médicos que irão utilizar no EAS. Para que essas abordagens sejam utilizadas de forma conjunta utilizou-se o Plano de Trabalho proposto pela Sociedade Americana de Engenharia de Valor (SAVE) para gestão do valor, que foi adaptado ao contexto da PM estudada e representado em mapa de processo (Figura 4).

No Plano de trabalho é previsto a realização de um Workshop, para Estudo de Valor, que deve ser realizado por todos os profissionais (ou líderes das equipes) envolvidos no empreendimento: arquitetos, engenheiros, agentes promotores, enfermeiros, médicos, entre outros. O Objetivo do Workshop é promover a interação entre as equipes multidisciplinares, incentivando a colaboração e a criatividade, essenciais para a abordagem do TVD. Para melhorar o entendimento do Workshop, as seis fases foram representadas separadas em diagramas BPMN.

\section{Desenvolvimento de ferramentas computacionais}

Nessa etapa da pesquisa realizou-se a adaptação de ferramental computacional de modelagem BIM para utilização no Método adaptado ao contexto dos EAS, tendo como base os processos praticados PMA do estudo de caso. Utilizou-se para isso o software Revit 2017 e um conjunto de planilhas do Excel vinculadas para o gerenciamento de valor no processo de desenvolvimento de projetos de UBS.

Figura 4: Plano de trabalho proposto pela SAVE

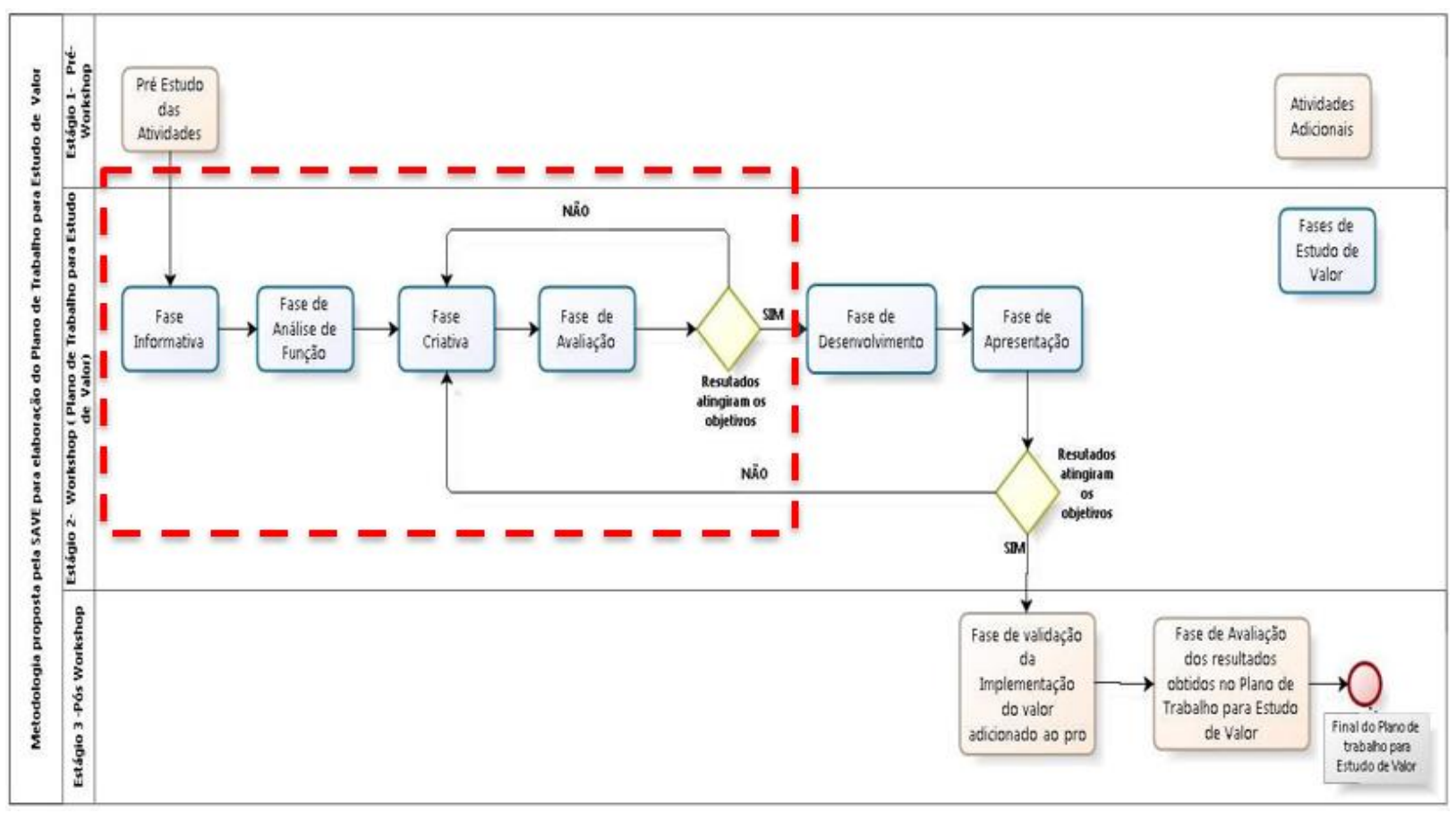

Fonte: Adaptado de SAVE (2007)

O desenvolvimento de um experimento prático na disciplina de pós-graduação Tópicos especiais: Modelagem da Informação da Construção e técnicas de colaboração avançada, teve como finalidade, verificar as potencialidades das ferramentas estudadas, a abordagem na abordagem do TVD no contexto de projetos de EAS no Brasil, por meio da experimentação de alternativas de projeto e a extração dos custos diretamente do modelo, permitindo a simulação custo-benefício, quase que em tempo real. 
Figura 5: Material disponibilizado pela prefeitura, plantas, cortes, fachadas e planilhas orçamentárias
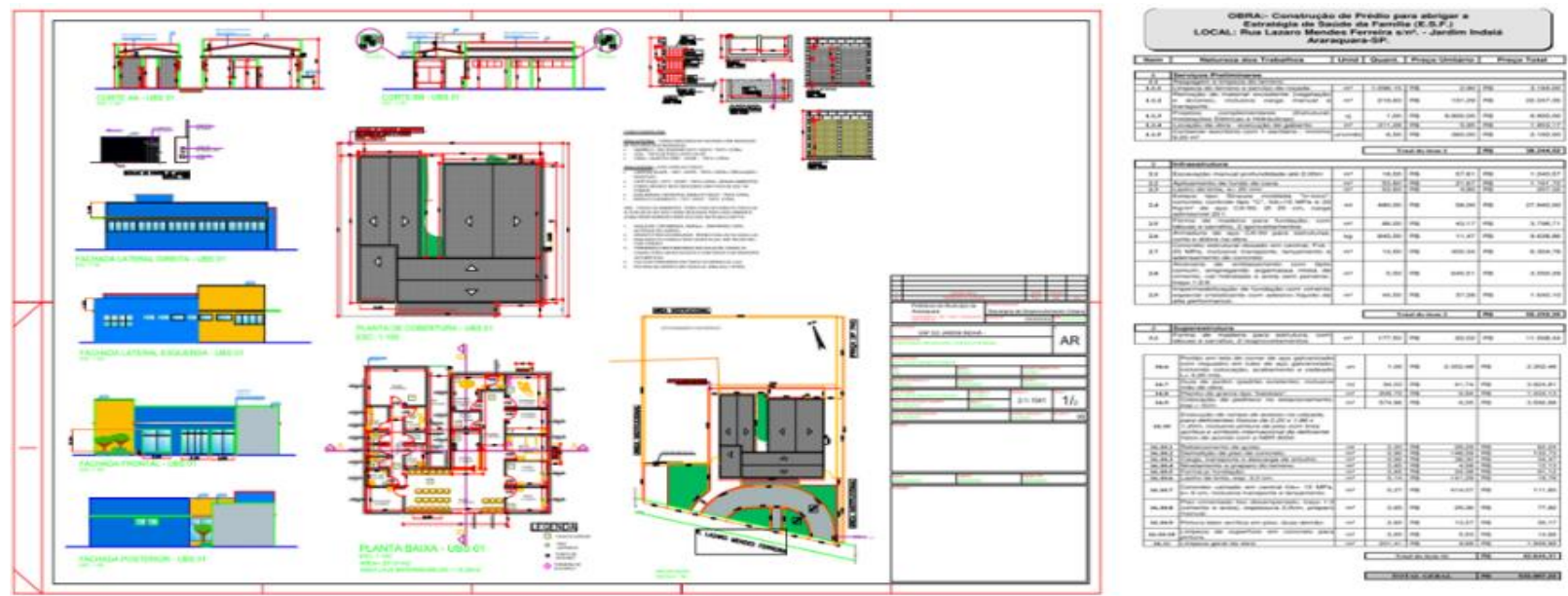

Fonte: Prefeitura Municipal Estudada, adaptado pelo autor (2017)

Para o desenvolvimento de uma atividade prática para os alunos de pós-graduação, houve a preocupação de trabalhar com um edifício de UBS real, que tivesse o maior número de informações referentes ao custo e a contextualização de seu processo de desenvolvimento (Figura 5).

Ao longo do processo de modelagem definiu-se como os quantitativos seriam exportados, para isso o modelo de informação da tipologia estudada foi decomposto em partes, de acordo com sua função, baseados na Norma de Desempenho NBR-15575. Os dados de composições de serviços e toda a Estrutura Analítica de Projeto (EAP), foram vinculadas as Key-notes e as famílias de objetos do software.

Figura 6: Ferramental Criado, modelo BIM e planilhas associadas
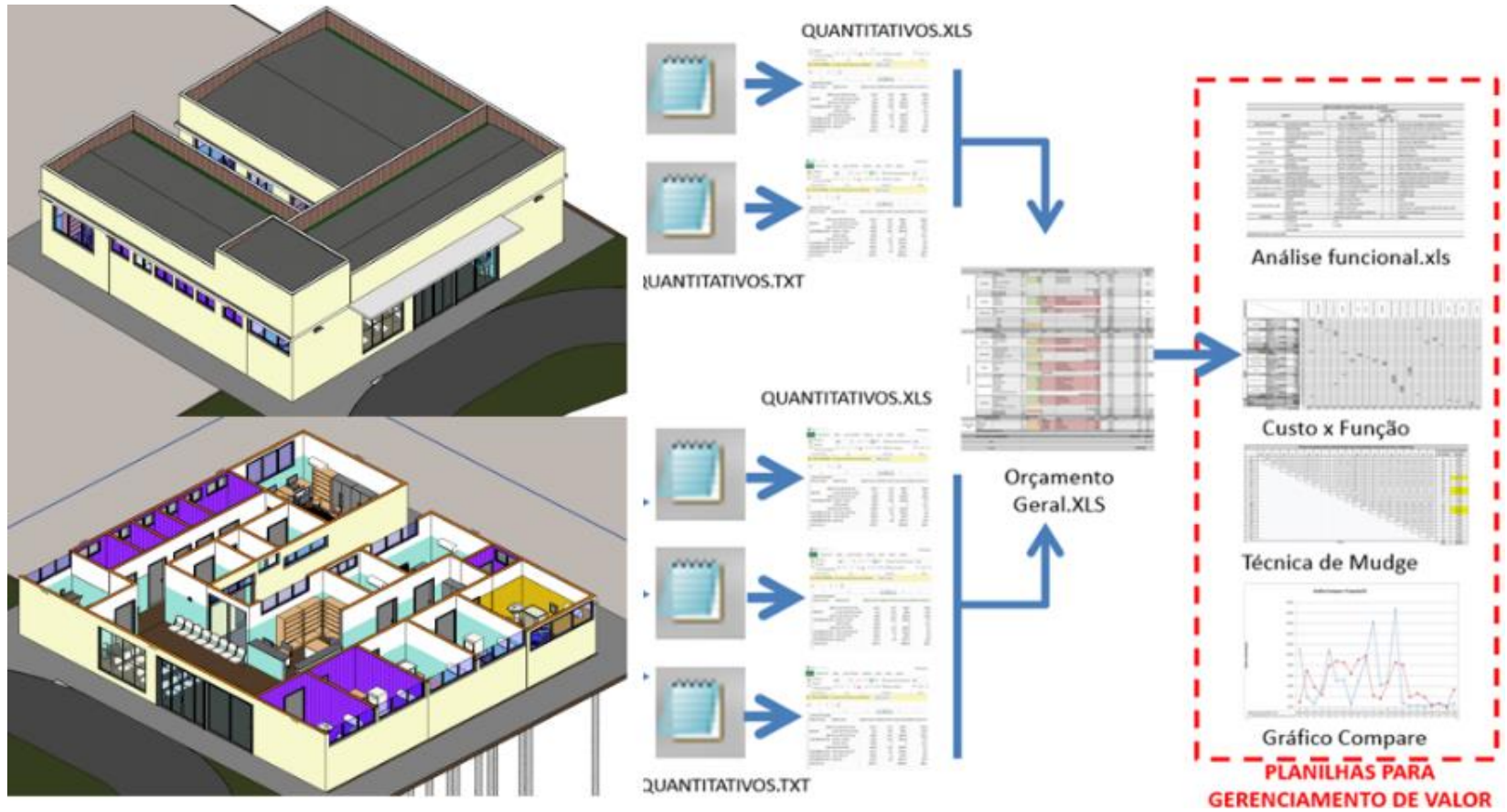

Fonte: Adaptado de Morais (2016) pelos Autores (2017)

Como o ferramental criado tem como finalidade subsidiar o processo de projeto da PMA, permitindo a comparação de dados quantitativos (custo) e qualitativos (valor), através do uso de modelos BIM e planilhas de gerenciamento de valor, as informações do modelo foram sistematizadas em planilhas do Excel, compostas pelas ferramentas de análise de valor:

- Análise Funcional;

- Técnica de Mudge; 
- e Gráfico Compare.

Os quantitativos e custos provenientes do Modelo BIM foram vinculadas as planilhas Excel através de arquivos de texto exportados diretamente do Revit. O processo para atualização dos custos pode ser resumido em três etapas principais, representadas na Figura 6.

\section{Prática Didática em Disciplina de Pós-Graduação}

No segundo semestre de 2017 o método e o ferramental criado foi testado na disciplina de pós-graduação "Tópicos Especiais: modelagem da informação da construção e técnicas de colaboração avançada (IAU5817). A disciplina teve como professor responsável Prof. Dr. Márcio Fabricio Minto e como colaboradores a Prof. ${ }^{a}$ Dr. ${ }^{a}$ Regina Coeli Ruschel e o Prof. Dr. Marcelo de Morais. O objetivo da disciplina foi preparar os alunos de pós-graduação para a utilização prática de técnicas de gerenciamento de valor (custo da solução de projeto $x$ qualidade entregue ao usuário) e práticas avançadas de colaboração, através do uso de modelos de informação da construção. Ao final, além do projeto, foi solicitado uma monografia sobre os conceitos e tecnologias abordadas e um relato analítico experiência projetual realizada, face à literatura revisada.

A disciplina foi realizada em seis semanas, e seu conteúdo foi dividido em duas aulas teóricas que abordaram os conceitos de Target Value Design, BIM e Set-Based Design, duas aulas expositivas com relato dos profissionais de projeto e enfermagem da UBS estudada, uma aula estendida para o desenvolvimento do Workshop de projeto e a última aula para a apresentação dos trabalhos. Além das aulas presenciais, os alunos receberam créditos trabalho para desenvolverem o projeto fora do horário da disciplina. Ao longo das aulas expositivas houve a participação de funcionários da Prefeitura Municipal de Araraquara, que participaram do processo de desenvolvimento da UBS estudada e utilizada como referência para o Workshop de projeto da disciplina.

Foram realizados dois relatos de experiência, o primeiro relacionado ao processo de desenvolvimento do UBS, abordando qual a sistemática adotada, o fluxo das informações e as principais dificuldades encontradas no processo. Para isso contamos com a participação da Arquiteta responsável pelo projeto, que foi Coordenadora de Projetos da Secretaria de Desenvolvimento Urbano, no período de desenvolvimento do projeto e construção da UBS. O segundo relato de experiência abordou o uso e ocupação da UBS, para isso, contamos com a colaboração do Enfermeiro Chefe da unidade, que atuava na época da construção da UBS, como gerente geral das Unidades Básicas de Saúde do Município e atualmente é o enfermeiro responsável pela operação da UBS estudada. A explanação do enfermeiro relatou os principais qualidade e problemas operacionais verificados na utilização da UBS, como: incompatibilidade do lay-out, dimensão reduzida dos ambientes, segurança e o conforto térmico do edifício, dentre outros.

Participaram da disciplina o total de 12 alunos, sendo um estudante do quarto ano de graduação em arquitetura, três Engenheiros Civis e oito Arquitetos. Os alunos foram divididos em Três grupos para o desenvolvimento do projeto e em equipes para a discussão das diretrizes e propostas para cada área: saúde, orçamentação e projeto (figura 7).

Figura 7: Distribuição dos grupos por equipe e área de trabalho

\begin{tabular}{ccccc}
\hline & GRUPO 1 & GRUPO 2 & GRUPO 3 & $\begin{array}{c}\text { TOTAL POR } \\
\text { ÁREA }\end{array}$ \\
\hline $\begin{array}{c}\text { EQUIPE DA ÁREA } \\
\text { DE SÁUDE }\end{array}$ & 1 & 1 & 1 & 3 \\
$\begin{array}{c}\text { EQUIPE DE } \\
\text { ENGENHARIA } \\
\text { (ORÇAMENTO) } \\
\begin{array}{c}\text { EQUIPE DE } \\
\text { PROJETO }\end{array}\end{array}$ & 1 & 1 & 1 & 3 \\
$\begin{array}{c}\text { TOTAL POR } \\
\text { GRUPO }\end{array}$ & 4 & 2 & 2 & 6 \\
\hline
\end{tabular}

Fonte: Autores (2017)

Três fases do plano de trabalho proposto pela Sociedade Americana de Engenharia de Valor (SAVE) foram realizadas ao longo do Workshop, a Fase Informativa, a Fase Análise funcional, a Fase Criativa (Figura 4). A Fase de Avaliação foi realizada com atividade externa e os resultados apresentados no último dia de aula. 


\section{RESULTADOS E DISCUSSÃO}

Em relação aos resultados referentes ao experimento prático realizado na disciplina IAU-5817, temos o método mapeado em BPMN utilizado no Workshop, o desdobramento das suas atividades e os projetos desenvolvidos pelos alunos de pós-graduação.

\section{Workshop de Projeto}

O Workshop proposto pela SAVE (Figura 4) para estudo de Valor foi simulado na sala de aula durante a disciplina de pós-graduação. Na simulação, os alunos assumiram o papel dos profissionais (ou líderes das equipes) envolvidos no desenvolvimento do projeto, no caso específico: os arquitetos, engenheiros da área de orçamentação e os representantes da área de saúde. O Workshop teve como objetivo incentivar a colaboração e interação entre as equipes multidisciplinares estimulando a criatividade através de brainstormings.

Para desenvolver os projetos os alunos utilizaram a sala do grupo de pesquisa (nome omitido para avaliação), especialmente preparado para apoiar as atividades de projeto. Na sala foram disponibilizados material de desenho, folhas de várias cores e tamanhos, post-it variados, blocos lego arquitetura para construção de maquetes e outras peças para simulação de volumetria. Também estavam disponíveis computadores com software Revit da Autodesk, SketchUp, Planilhas MS-Excel, outros softwares auxiliares. Os alunos também puderam contar com três mesas digitalizadora de 27 polegadas para desenvolvimento de sketch ou manipulação do projeto em BIM com auxílio de caneta gráfica.

Participaram do Workshop, além dos três professores da disciplina, os doutores César Imai, Ana Regina Mizrahy Cuperschmid e Michele Caroline Bueno Ferrari Caixeta, que poderiam ser consultados pelos alunos para discussões, respectivamente, projeto de EAS, questões volumétricas e percepção do usuário, uso de software BIM.

As Fases iniciais do Workshop proposto pela SAVE como Fase Informativa (Figura 8), Fase de Análise Funcional (Figura 10) e Fase Criativa (Figura 13) foram iniciadas do dia 14 de setembro ao longo do dia todo no Workshop de projeto e a Fase de Avaliação (Figura 14), foi realizada pelos alunos para finalização dos projetos apresentados na disciplina de pós-graduação.

O "Método para utilização de BIM apoiando Target Value Design na concepção de Estabelecimentos Assistenciais de Saúde" foi sistematizado para auxiliar e conduzir o processo de desenvolvimento de novos edifícios da área da saúde e leitura e releitura de alternativas de projeto da UBS, com base em variáveis de custo $\mathrm{X}$ valor percebido. Como parte de um caso real de determinado projeto, de determinado município, $\mathrm{O}$ método pode ser adaptado, mas deve ser recontextualizado para novas aplicações.

Figura 8: Fase Informativa

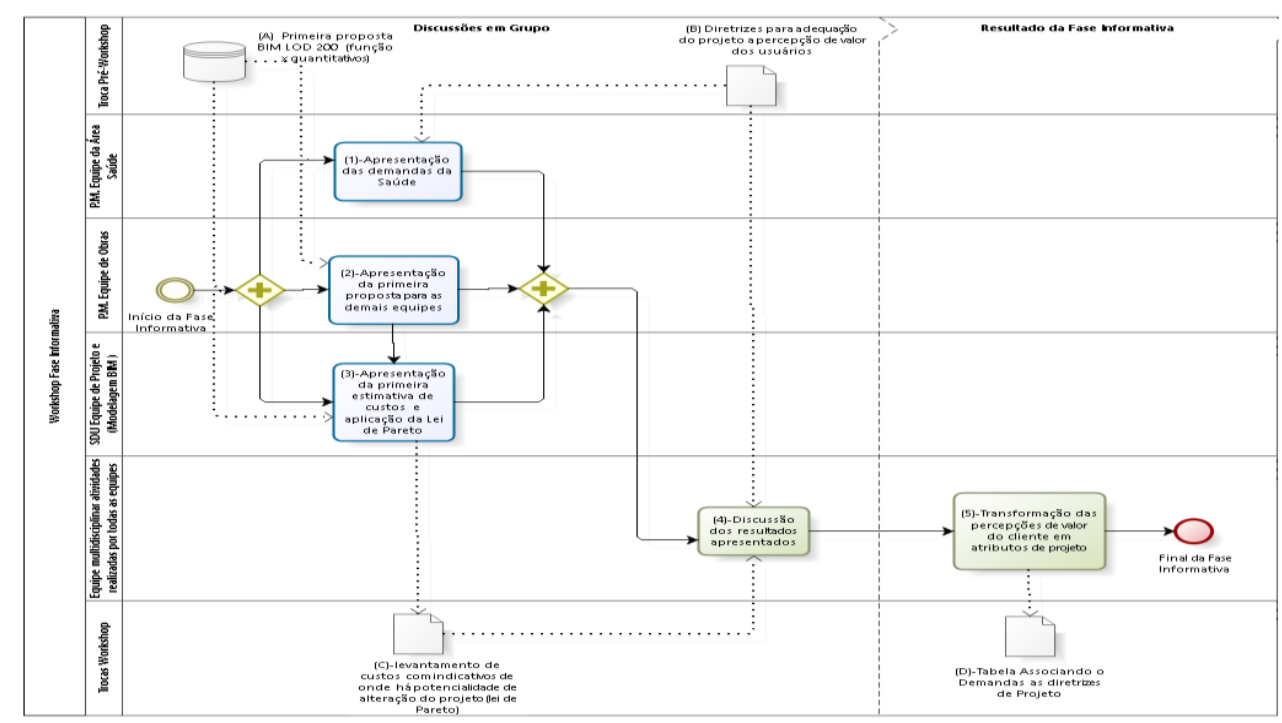


As atividades previstas no plano da SAVE para o Pré-Workshop, a Fase de Desenvolvimento e Fase de Apresentação e Pós-Workshop, não foram realizadas na disciplina, porém foram sistematizadas em BPMN e podem contribuir no processo de desenvolvimento de novos projetos da PM estudada ou para adaptação para contextos diferentes.

A primeira fase desenvolvida no Workshop foi a Fase Informativa (Figura 8) que tem como objetivo a compreensão de todos os participantes do projeto que será desenvolvido.

Figura 9: Equipes da área de saúde, projeto e orçamentação explanando os pareceres por área

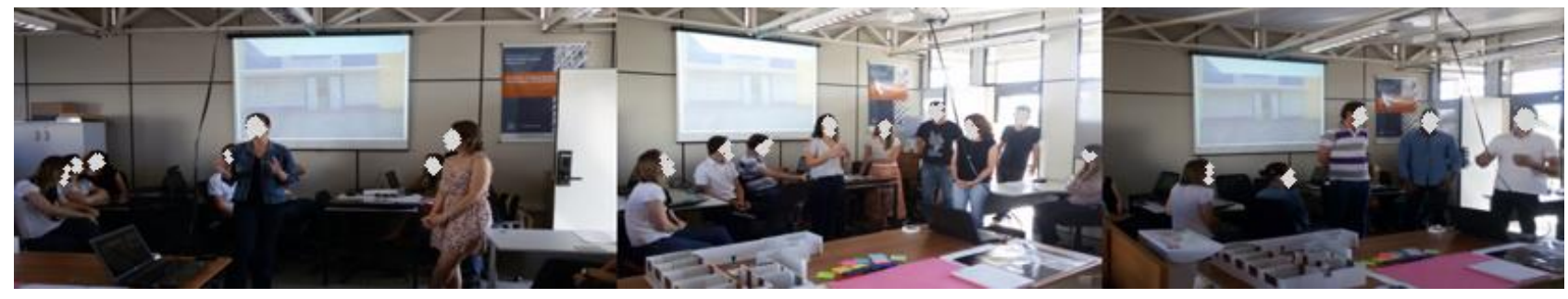

Fonte: Autores (2017)

Para que isso ocorra é necessário a apropriação de cada equipe de sua expertise, a Equipe da área de saúde apresenta, para os membros das demais equipes, os dados que caracterizam os usuários da UBS, os principais problemas operacionais e as restrições legais como RDC 50. A Equipe de Projeto apresenta a primeira proposta para o projeto, no caso específico a UBS construída em 2015 no Município de Araraquara. A Equipe de Engenharia e orçamentação faz uma explanação geral dos custos verificados no orçamento fornecido pela prefeitura, analisando os custos segundo o princípio de Pareto e os custos por funções, verificando os itens que tem potencialidade de serem alterados no projeto.

Para dar início ao Workshop é essencial o desenvolvimento das atividades previstas no Pré-Workshop que contempla a elaboração do primeiro estudo para o projeto, modelado em BIM, as planilhas orçamentárias e de gerenciamento de valor já vinculadas ao modelo.

Após apresentação do projeto, caracterização dos usuários, e as primeiras estimativas de custos, os Grupos uniram-se e discutiram os resultados apresentados e, posteriormente, elaboraram as diretrizes de projeto, que levam em consideração as percepções de valor do usuário.

Em seguida, o próximo passo foi a realização da Análise Funcional (Figura 10), que tem como objetivo aplicar as ferramentas de engenharia de valor no projeto. O primeiro passo dessa fase é decompor o produto em funções e classificá-las. Posteriormente é feita a avaliação das relações funcionais, sendo que para realizar a hierarquização das funções deve-se seguir a sua ordem de importância (funções básicas, secundárias ou secundárias necessárias, funções de uso ou estima). Facilitando, assim, a tomada de decisão relativa às alterações que podem ser mais expressivas, sem prejudicar a funcionalidade do edifício.

Os critérios seguidos no Workshop foram sistematizados através da Análise Funcional proposta por Dell'Isola (1997), que classifica as funções em três tipos básicos: Funções Básicas (FB), Funções Secundárias Necessárias (FSN) e Funções Secundárias (FS). Posteriormente deve-se definir ainda se as funções são de uso ou estima. Devido ao curto espaço de tempo do Wokshop, infelizmente não houve um aprofundamento maior no uso das ferramentas de valor, alguns Grupos passaram a rever Analise Funcional pré-elaborada e as demais ferramentas para gerenciamento de valor utilizadas (Figura 10). 
Figura 10: Fase Análise Funcional

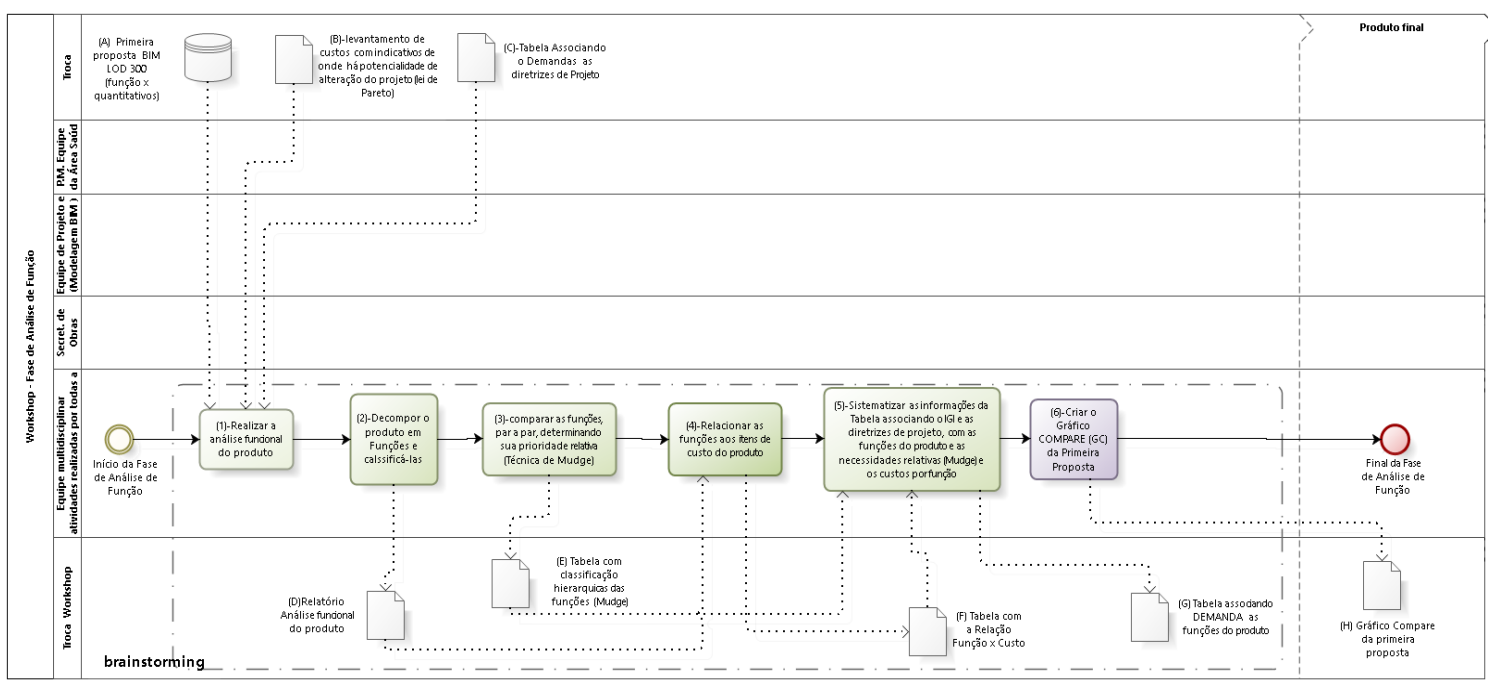

Fonte: Autores (2017)

Csillag (1995) afirma que as técnicas de análise funcional contribuem para a melhoria do Gerenciamento do Valor, são essenciais para projetar e reprojetar um determinado produto e buscam atender as necessidades dos usuários.

Os principais produtos gerados nessa fase são criados a partir das ferramentas de gerenciamento de valor como: a tabela com a Análise Funcional, a Distribuição dos custos nas Funções (referente aos dados quantitativos do projeto - consumo de recursos), a avaliação numérica das funções ou Técnica de Mudge (referente aos dados qualitativos do projeto - necessidades relativas) e finalmente o Gráfico Compare (Figura 11).

O Gráfico Compare é resultado de um método baseado na análise dos custos alocados em cada função e da técnica de Mudge. Os resultados coletados pelas ferramentas são sistematizados e representados na forma de gráfico. Desta forma, trabalha-se o gerenciamento dos custos tendo como parâmetro as relações entre as funções e o valor atribuído aos usuários (CSILLAG, 1995). O ponto de equilíbrio do gráfico é a sobreposição das necessidades relativas (azul) ao consumo de recursos (verde para a proposta inicial e laranja para as alterações realizadas pelos alunos).

Figura 11: Ferramentas utilizadas para Gerenciamento de Valor, Dados a partir do projeto real da UBS (ver anexos).

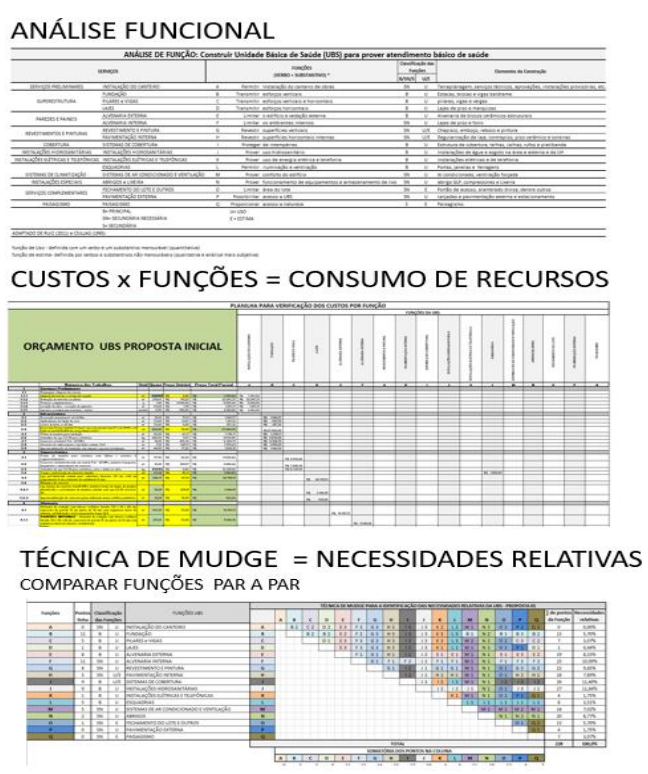

\section{GRÁFICO COMPARE}

Consumo de recursos $\mathrm{x}$ necessidades relativas
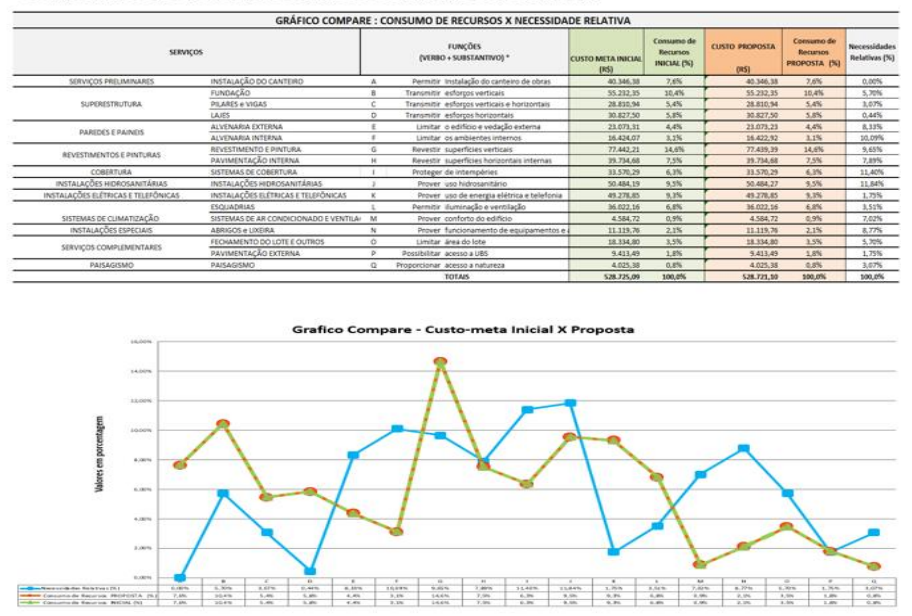

Fonte: Autores (2017) 
Figura 12:Interação e discussão entre as equipes ao longo da Fase Criativa
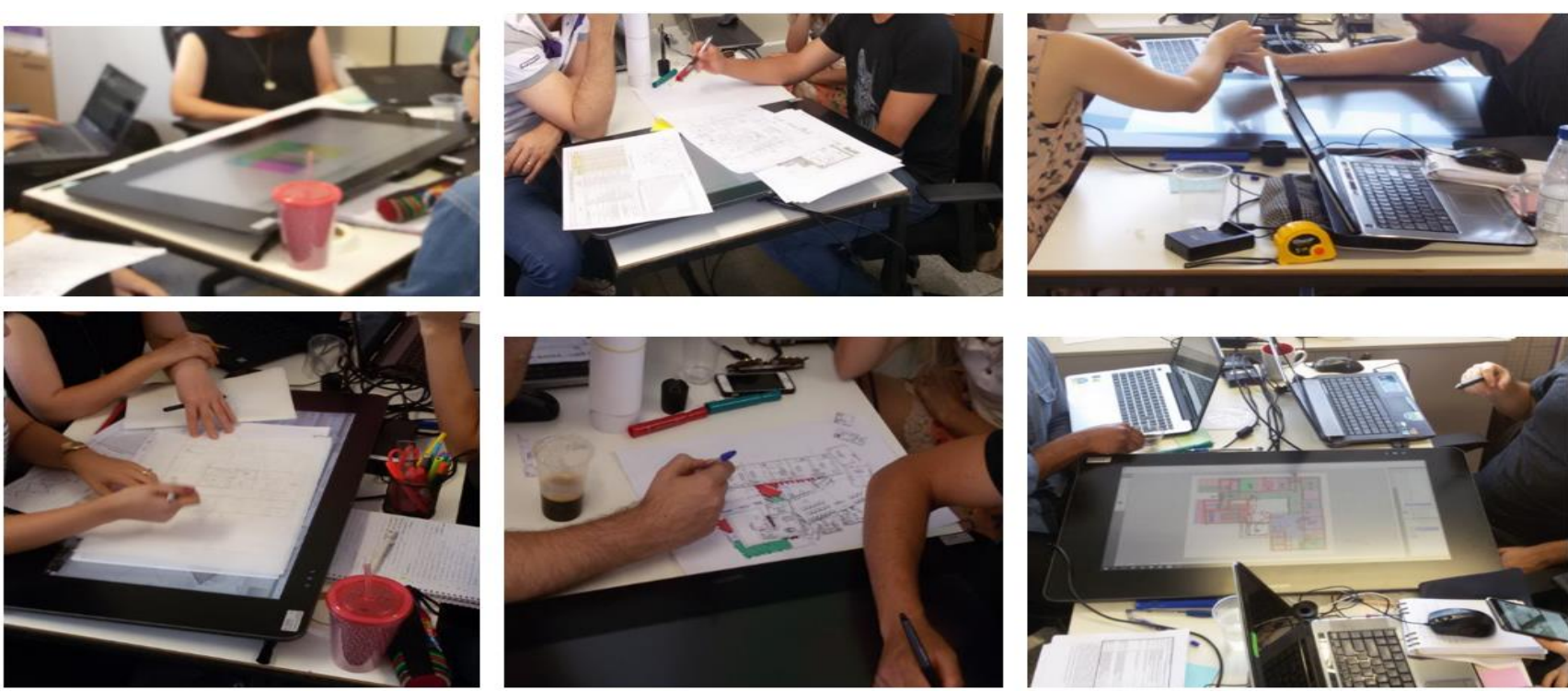

Fonte: Autores (2017)

Com as informações realizadas no Gráfico é possível verificar se há equilíbrio entre o consumo de recursos e as necessidades relativas dos usuários, como no caso da Função A - Instalação do canteiro, que consome $7 \%$ dos recursos e representa $0 \%$ das necessidades relativas dos usuários, sendo um dos itens que, ao ser modificado, pode acrescentar valor ao projeto aos olhos do usuário.

Após a Fase Análise Funcional é realizada a Fase Criativa (Figura 13), que abrange como se deve estimular a inventividade da equipe e gerar o máximo de ideias sobre o projeto.

Os Grupos se unem para um brainstorming multidisciplinar, com a finalidade de agregar sugestões para criação de novas soluções, uma das perguntas frequentes dessa fase é quais são as possibilidades ou maneiras diferentes de se executarem as mesmas funções do produto, como troca de sistema construtivo, readequação dos ambientes, alteração do lay-out, entre outras estratégias de melhoria (Figura 12).

Figura 13: Fase Criativa

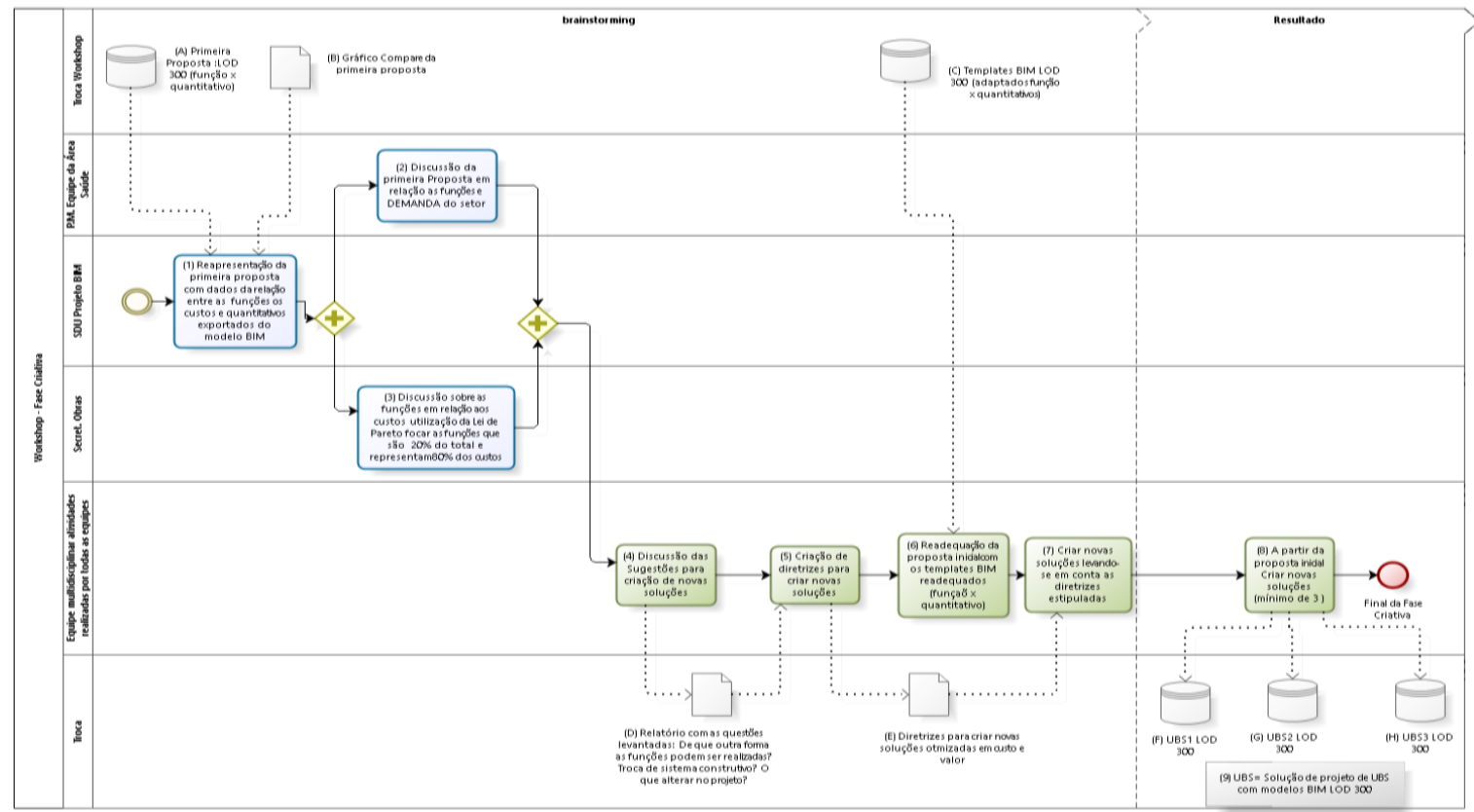

Fonte: Autores (2017) 
Espera-se nessa fase que a partir da proposta inicial desenvolvida em BIM sejam criadas novas soluções de projeto por Grupo, tendo assim três alternativas (itens F, G e H - Figura 13) para serem avaliadas e comparadas na fase seguinte, seguindo os princípios do Set-Based Design (SBD).

Figura 14: Fase Avaliação

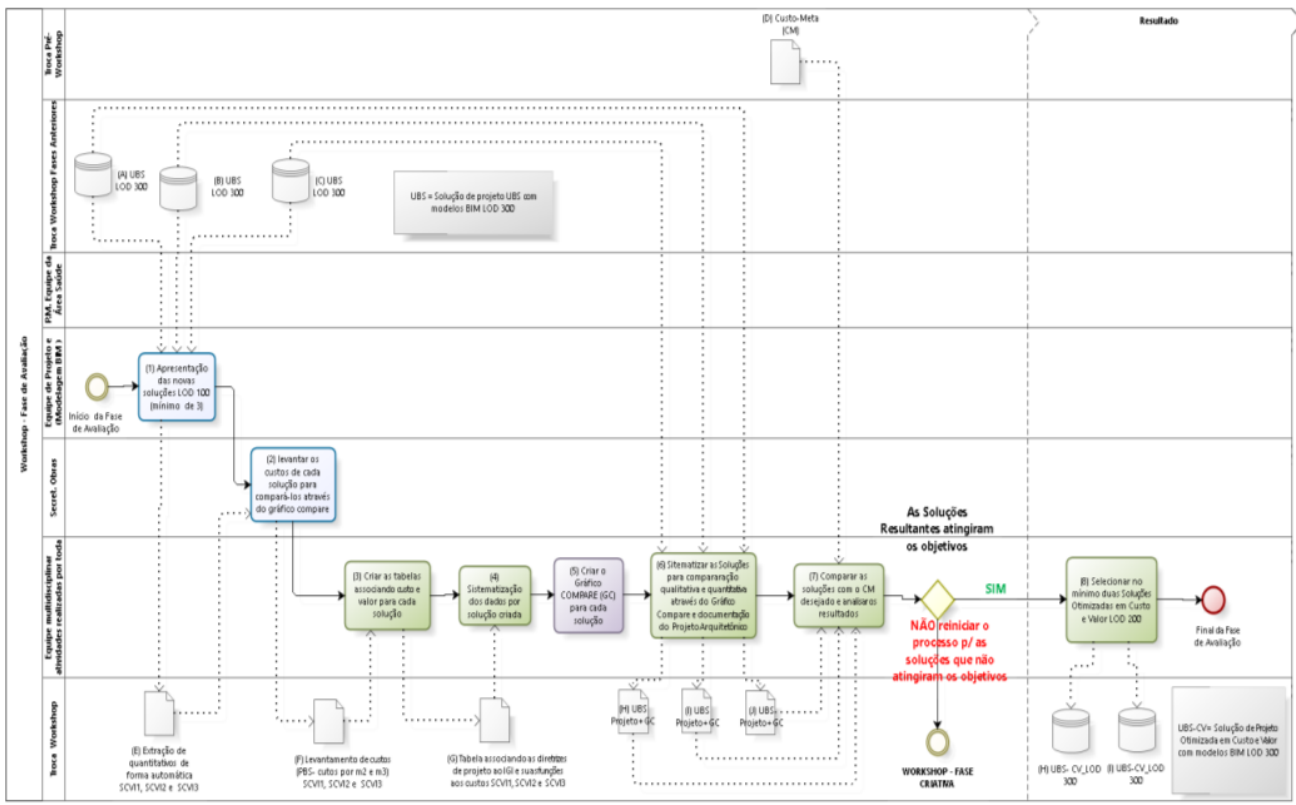

Fonte: Autores (2017)

A Fase de Avaliação (Figura 14) foi desenvolvida fora do Workshop e o resultado foi apresentado pelos Grupos no formato de pôsteres, e um vídeo descrevendo a propostas. Os produtos avaliados nessa fase foram o projeto arquitetônico representado através do Modelo Bim e a sistematização do Gráfico Compare.

No dia das apresentações houve, ainda, uma discussão entre todos os alunos e professores, sobre se haveria possibilidade de redução da quantidade de ideias propostas, quais as alternativas ou soluções poderiam ser desenvolvidas em conjunto, para agregar mais valor ao produto, e que mantinham a coerência com o custometa (custo da UBS segundo a PM estudada).

Em relação aos resultados alcançados no Grupo 1 (Figura 15) temos a redução em torno de $17 \%$ do custo total da obra, e o acréscimo na área construída, que passou de 213,69 m², e ficou com 245,00 m².

Figura 15: Planta, modelo Bim, custos finais e Gráfico Compare - Grupo 1
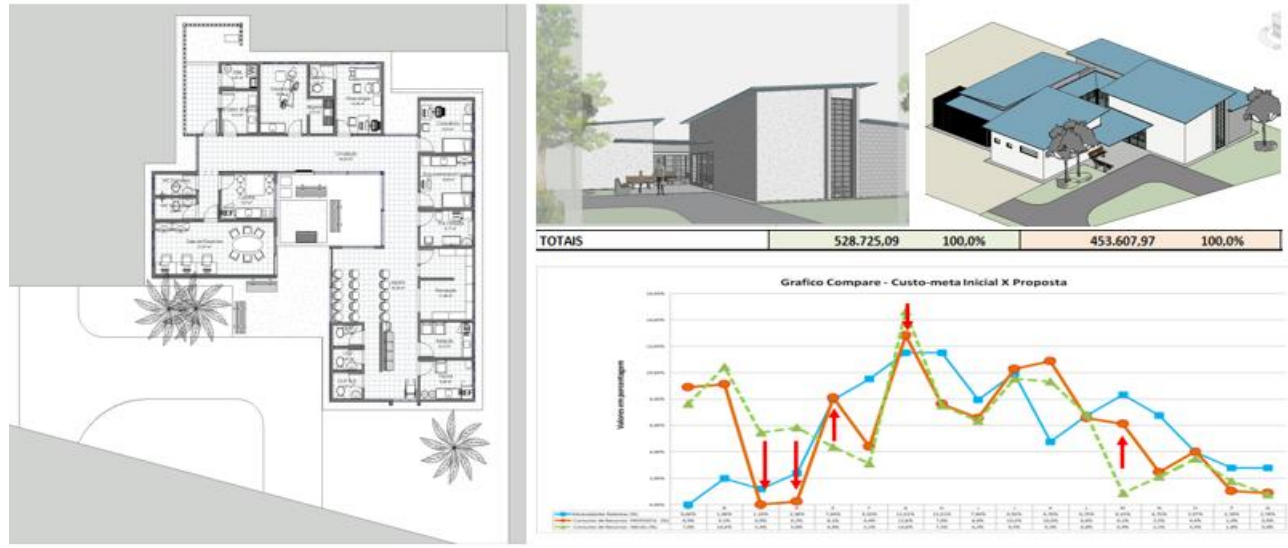

Fonte: Fonte: Montagem dos Autores, a partir das imagens e dados desenvolvidos pelo Grupo 1 (2017) 
Os itens que impactaram na economia gerada na obra foram: A diminuição no prazo de Instalação do canteiro, através da racionalização da obra, função essa que agrega pouco valor ao usuário; houve a troca do sistema de cobertura por telhas térmicas e eliminação das lajes de forro, impactando na estrutura e fundação do projeto, e no conforto ambiental do edifício; a solução adotada utilizou blocos estruturais de concreto e em pontos específicos houve a eliminação do revestimento externo e os dados provenientes da ferramenta Técnica de Mudge foram reavaliados.

Como uma das medidas que contribuem para a humanização do ambiente foi a criação de um jardim interligando área interna e externa do edifício à recepção.

Em relação às medidas operacionais, o Grupo 1 concentrou as atividades de saúde isoladas da recepção e Isolou o Expurgo do resto dos ambientes.

Na proposta apresentada pelo Grupo 2 (Figura 16) houve a redução em torno de 2,2\% do custo total da obra, o acréscimo na área construída, que ficou com $290 \mathrm{~m}^{2}$.

Figura 16: Planta, modelo Bim, custos finais e Gráfico Compare - Grupo 2

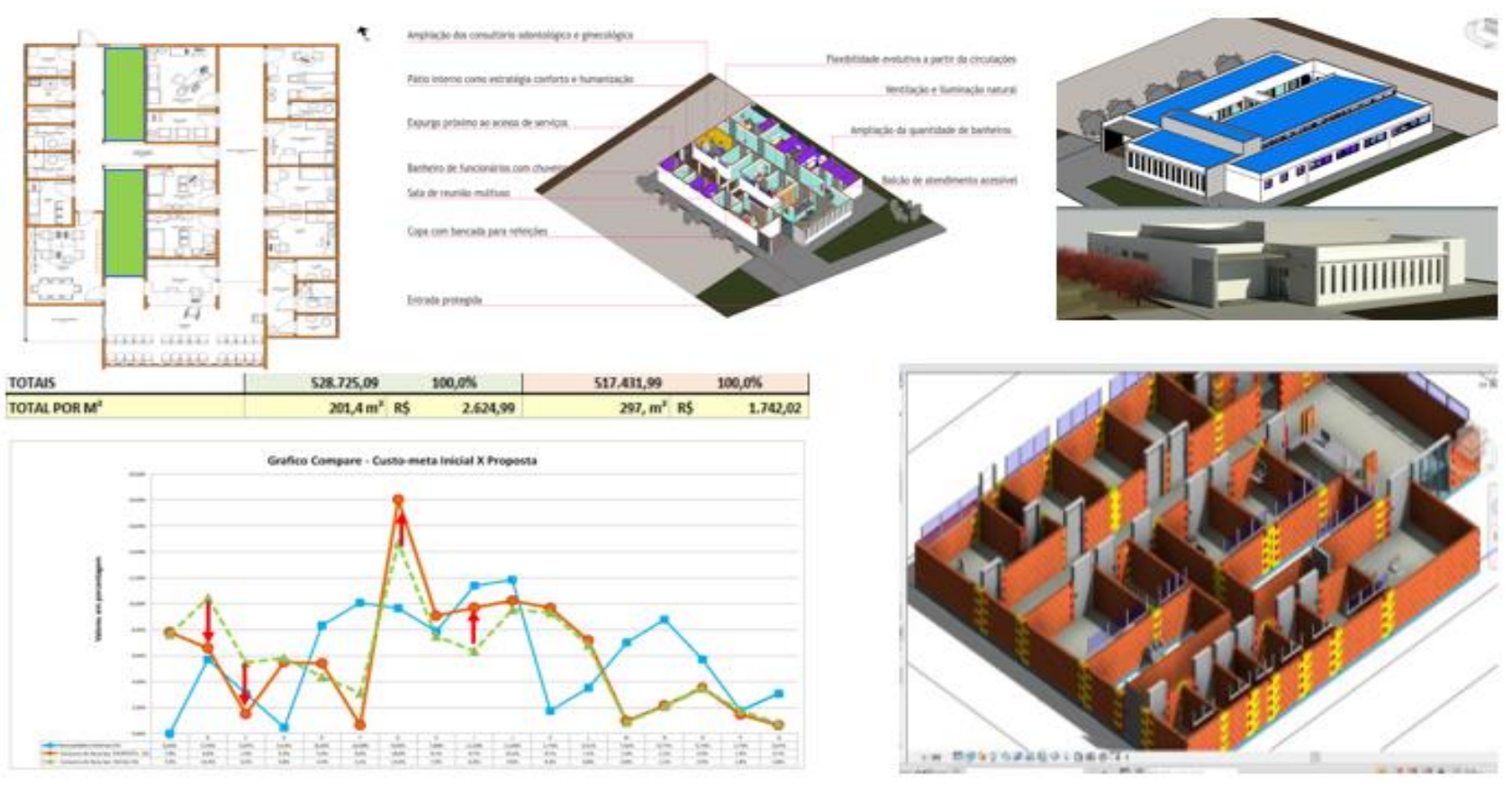

Fonte: Montagem dos Autores, a partir das imagens e dados desenvolvidos pelo Grupo 2 (2017)

Os itens que impactaram na economia gerada na obra foram: a diminuição no prazo de Instalação do canteiro, através da racionalização da obra com a troca do sistema construtivo e da fundação, funções essas que agregam pouco valor ao usuário; redução do resíduo proveniente da obra; a ampliação da área construída com a redução do custo por $\mathrm{m}^{2}$; a solução adotada utilizou blocos estruturais cerâmicos que foram modelados em BIM.

A principal medida que contribuiu para a humanização do ambiente foi a criação de um jardim Interno, proporcionando ventilação e iluminação zenital ao edifício.

Em relação às medidas operacionais o Grupo 2 ampliou os consultórios, propôs a flexibilização do projeto prevendo futuras ampliações e isolou o expurgo das demais atividades da UBS.

Já na proposta apresentada pelo Grupo 3 (Figura 17) houve um acréscimo em torno de 7\% no custo total da obra, e a área construída total ficou em $330 \mathrm{~m}^{2}$. 
Figura 17: Planta, modelo Bim, custos finais e Gráfico Compare -Grupo 3
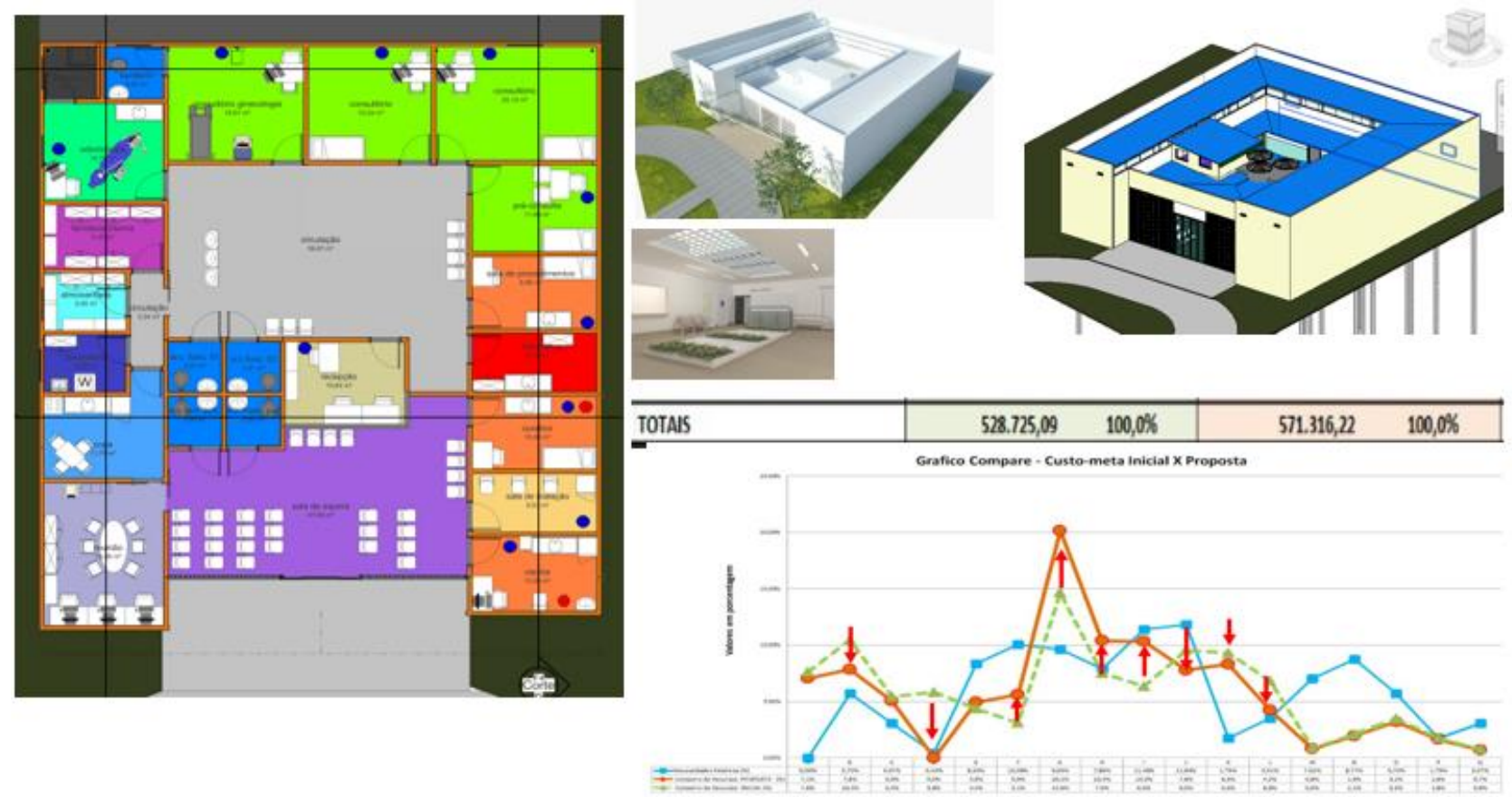

Fonte: Montagem dos Autores, a partir das imagens e dados desenvolvidos pelo Grupo 3 (2017)

Diferenciando-se dos projetos anteriores apresentados não houve economia no custo total da obra, o Grupo 3 justificou o aumento de custo devido à ampliação do programa criando uma farmácia e uma copa, destinada para as refeições dos funcionários.

As principais soluções adotadas pelo grupo foram: o uso de laje forro nos consultórios e ambientes de atendimento da UBS e telhas térmicas nas áreas de circulação, criando iluminação e ventilação permanente no edifício.

Nas questões relacionadas à humanização destaca-se a criação de um grande pátio interno, que tem a finalidade de facilitar a triagem dos usuários da UBS, sendo um apoio para a recepção após a primeira triagem.

Em relação às medidas operacionais, houve a ampliação do programa, a definição de locais de acesso restrito aos funcionários, a criação do passa-expurgo, isolando o mesmo dos demais ambientes e as duas recepções com fluxos diferenciados.

Verificou-se, nos resultados dos projetos apresentados na disciplina de pós-graduação, um empenho dos alunos para alcançarem as metas de custo propostas no orçamento fornecido pela prefeitura e o atendimento do valor ao usuário, como pode ser observado na variação apresentada no Gráfico Compare. Apenas o Grupo 3 não conseguiu realizar as modificações sem conter os custos.

Para a avaliação final dos alunos na disciplina, foram analisadas a participação dos alunos no Workshop, os modelos e simulações desenvolvidos, as propostas apresentadas (apresentação oral, pôsteres e vídeo) e a monografia reflexiva com os tópicos discutidos na disciplina.

\section{CONSIDERAÇÕES FINAIS}

No Brasil não é usual disciplinas de pós-graduação em arquitetura que tenham como objetivo o desenvolvimento de projetos. Muitos argumentam que o tipo de pesquisa desenvolvida para realização de um projeto de arquitetura não é de cunho científico, porque não expande a fronteira do conhecimento, limitandose a buscar soluções para questões específicas do projeto em curso. Entretanto, novas abordagens metodológicas ligadas à ciência do artificial, como o Design Science Research, reconhece como pesquisa científica o desenvolvimento de artefatos (projetos) inovadores, desde que acompanhados de uma discussão e proposição teórica que amplie as fronteiras consagradas de determinado campo do saber.

Outra questão polêmica nos exercícios acadêmicos de projeto de arquitetura é colocar os custos reais de construção como centrais no processo de projeto e de tomada de decisão. Neste caso, o argumento é que 
custos tolhem a liberdade criativa e limitam o desenvolvimento do projeto. Outro argumento é que a realidade profissional irá condicionar os profissionais a projetos contingenciados pelos custos e que a universidade deve permitir uma abordagem mais utópica das questões de projeto. Sem negar a conveniência de exercícios acadêmicos - projetuais que explorem utopias, é também importante que a universidade discuta e proponha exercícios para problemas reais, nos quais os custos de construção e operação das edificações são variáveis centrais.

A partir destes dois enfretamentos, o exercício projetual partir das discussões teóricas sobre colaboração em BIM e TVD em projeto de EAS. Outro insumo foi a apresentação e discussão com diferentes aportes de um projeto real que serviu de referência inicial para o exercício projetual.

A apresentação de um projeto já edificado e toda sua problemática, foi essencial para os resultados de projeto apresentados pelos alunos, sem essa inserção seria difícil verificar os benefícios da utilização conjunta das práticas de projeto integrado "Método para utilização de BIM apoiando Target Value Design na concepção de Estabelecimentos Assistenciais de Saúde".

O relato de experiência da Arquiteta responsável pelo desenvolvimento do projeto da UBS, demonstrou as dificuldades no desenvolvimento de projetos no setor público, bem como a burocracia arraigada a esse processo, o que por sua vez incentivou os alunos a adotarem as práticas colaborativas do método, buscando assim correlacionar as decisões de custos e valor ainda nas fases iniciais de desenvolvimento de projeto. $O$ relato de experiência do Enfermeiro responsável pela UBS na disciplina de pós-graduação e as entrevistas com os usuários na UBS (agentes comunitários, técnicos de enfermagem e o médico) foram essenciais para alimentarem dados, referentes à percepção de valor dos usuários da UBS, e serviram como referência para as diretrizes de projeto discutidas no dia do Workshop.

Apesar do prazo pequeno, duas semanas, para a entrega dos projetos, os alunos de pós-graduação, obtiveram um resultado positivo, em termos de propostas e custos apresentados. Rompendo com o padrão usual de projeto, caracterizado pela orçamentação realizada no final do processo. A experiência prática realizada demonstrou a potencialidade do uso do ferramental e do método para o desenvolvimento do projeto da UBS, observou-se ainda a preocupação no atendimento às necessidades dos usuários, como pode ser observado, comparando os resultados no Gráfico Compare.

Ao longo do workshop foi possível verificar a ampla interação entre as equipes e grupos devido às fases elencadas no método, criando papéis e regras para a interação entre as pessoas. A experiência mostrou-se produtiva e os brainstorming propostos no método, estimularam a discussão entre os grupos e a criatividade dos participantes.

Já em relação à extração dos quantitativos diretamente do modelo BIM, criado como referência de projeto (UBS"), conseguiu-se uma eficiência de $61,5 \%$ dos custos totais. Esses resultados podem ser considerados positivos, pois podem em muito contribuir para o processo de desenvolvimento de novos projetos da PMA, agilizando o processo de orçamentação. Dentre os itens que não foram modelados estão as instalações hidráulicas e elétricas, o que despenderia muito tempo inviabilizando a proposta do Workshop realizado.

Verificou-se na adaptação dos instrumentos, a dificuldade em relação à interoperabilidade entre o software de arquitetura e as planilhas do Excel. Apesar dos benefícios verificados ao longo do experimento, os links realizados em arquivos de texto com as planilhas do Excel, efetivados de forma unidirecional, representam um grande gargalo para o fluxo da informação, necessitando maior desenvolvimento do ferramental nesse sentido. Outro problema verificado foi a falta de dados de custos sistematizados para novos sistemas construtivos e específicos para a área hospitalar, isso exigiu um esforço para criação de parâmetros adicionais de custos, diferentes dos encontrados no SINAPI, VOLARE e na PINI. A fim de superar esse obstáculo, foram realizadas adaptações dos dados encontrados nessas bases de custos.

Os resultados obtidos até o momento deverão subsidiar novas pesquisas relacionadas ao ensino de projeto, contribuindo para reflexão sobre o uso das práticas integradas de projeto com TVD e BIM, no cenário de simulação de custo para a gestão do valor em edifícios de assistência à saúde.

Pode-se verificar através da pesquisa realizada junto a Prefeitura Municipal a necessidade de uma readequação do fluxo de trabalho no processo de desenvolvimento de projetos, todo baseado em sistemas CAD, os quais são baseados na representação bidimensional do projeto e não possuem informações agregadas em seu processo de desenvolvimento, somente dados sobre a geometria do projeto. O que dificulta a tomada de decisão ainda nas fases iniciais e projeto. Desta forma, o Método proposto, utilizado em conjunto com o ferramental criado, tem grande potencialidade para melhorar o fluxo de trabalho e a qualidade da informação no processo de desenvolvimento de projeto realizado pela PMA. 
Com a utilização de ferramentas que permitem BIM e práticas colaborativas de projeto como TVD, sendo implantadas de forma ampla na área de saúde por empresas de construção civil, nos EUA, novas posturas deverão ser adotadas para potencializar seu uso no desenvolvimento de projetos. Desta forma pode-se vislumbrar a potencialidade da aplicação prática dos artefatos e dinâmica adotada na disciplina de pósgraduação, abrindo perspectivas para a utilização de novas tecnologias, contribuindo assim, para sua aplicação na prática no processo de ensino e desenvolvimento de edifícios de assistência à saúde.

\section{Agradecimentos}

Os autores agradecem ao CNPq, pela concessão de um bolsa de pós-doutorado; aos profissionais da Prefeitura Municipal de Araraquara, que contribuíram no fornecimento de material e participação na disciplina de pós-graduação e aos alunos da disciplina de pós-graduação Tópicos especiais: Modelagem da Informação da Construção e técnicas de colaboração avançada (IAU-5817-USP), que tanto contribuíram para o desenvolvimento deste experimento.

Aos doutores César Imai, Ana Regina Mizrahy Cuperschmid e Michele Caroline Bueno Ferrari Caixeta que atuaram como consultores de projeto durante o workshop.

\section{REFERÊNCIAS}

ANVISA_- Agência Nacional de Vigilância Sanitária. Resolução - RDC no 50, de 21 de fevereiro de 2002. Disponível em: $<<$ http://www.anvisa.gov.br/anvisalegis/resol/2002/50 02rdc.pdf $>>$ Acessado em janeiro de 2018.

ALARCON, I.; CHRISTIAN, D.; TOMMELEIN, I. D. Collaborating With a Permitting Agency to Deliver a Healthcare Project: Case Study of The Sutter Medical Center Castro Valley (SMCCV). In: Annual Conference of the International Group for Lean Construction (IGLC), 13,. 2005, Sydney. Proceedings... Sydney: jul. 2005. v. 1. p.153-160.

BALLARD, G.. The Lean Project Delivery System: an update. Lean Construction Journal, Lean Construction Institute, p 1 19, 2008. Disponível em:< http://www.leanconstruction.org/lcj/2008/LCJ 08 001.pdf.> Acesso em: 05 nov. 2010

BITENCOURT, F. A Sustentabilidade em ambientes de saúde: um componente de utopia ou de sobrevivência? In: Quem tem medo da Arquitetura Hospitalar? Organizador: Antonio Pedro Alves de Carvalho. Salvador: FAUFBA, 2006. p. 13-48.

BITENCOURT, F; COSTEIRA, E (Org.). Arquitetura e Engenharia Hospitalar, editora Rio Books, 2015, 410 p.

BROSS, J. C. Compreendendo o Edifício de Saúde, editora Atheneu, 2013, 270 p.

CONSELHO FEDERAL DE MEDICINA. Falta de leitos e de estrutura de atendimento agravam crise na rede pública. Brasília, $24 \quad$ out. $2011 . \quad$ Disponível em: http://portal.cfm.org.br/index.php?option=com content\&id=22337:falta-de-leitos-e-de-estrutura-de-atendimento-agravamcrise-na-rede-publica> Acesso em:04 ago. 2015.

COOPER, R.; SLAGMULDER, R. Target costing and value engineering, Portland: Productivity Press, 1997, 379 p.

CSILLAG, J.M. Análise do Valor. 4 Ed ampl e atual com novas tendências gerenciais. Atlas. São Paulo - SP, 1995. 284p.

CUNHA, Luiz Claúdio Rezende. A cor no ambiente hospitalar. Anais do I Congresso Nacional da ABDEH - IV Seminário de engenharia clínica. 2004, anais..., Salvador, 2004 . Disponível em: <http://bvsms.saude.gov.br/bvs/publicacoes/cor ambiente hospitalar.pdf> Acesso em: 10 ago. 2016.

DELL'ISOLA, A.P.E.. Value Engineering: Practical Applications for Design, Construction, Maintenace \& Operations. RS Means. Kingstone MA, 1997. 427p.

EASTMAN, C.; TEICHOLZ, P.; SACKS, R.; LISTON, K. BIM Handbook: A guide to Building Information Modeling for owners, managers, designers, engineers, and contractors. 2nd ed, Hoboken, New Jersey: John Wiley \& Sons, 2011. 650 p.

GOES, Ronald de. Manual Prático de Arquitetura Hospitalar. [S.L]: Edgard Blucher, 2004.

GIRIBOLA,M. Arquitetura Hospitalar: projetos e detalhes. Au - Arquitetura e urbanismo, v. 247, p. 2-7, out. 2014. Disponível

em:<http://www.au.pini.com.br/arquitetura-urbanismo/247/arquitetura-hospitalar-projetos-e-detalhes-327526-1.aspx > Acesso em: 10 out. 2016

JACOMIT, A.M.; GRANJA, A.D. An Investigation into the Adoption of Target Costing on Brazilian Public Social Housing Projects. Architectural Engineering and Design Management, v. 7, n. 2, p. 113-127, 2011.

KHANZODE, A.; FISCHER, M.; REED, D. Case study of the implementation of the Lean project Delivery System (Ipds) using virtual building technologies on a large healthcare project In: Annual Conference of the International Group for Lean Construction (IGLC), 13,. 2005, Sydney. Proceedings... Sydney: jul. 2005. v. 1. p.153-160. 
KHEMLANI, L. Sutter Medical Center Castro Valley: Case Study of an IPD Project. AECbytes: Building the Future, v. 6 , mar. 2009. Disponível em: <http://www.aecbytes.com/buildingthefuture/2009/Sutter IPDCaseStudy.html >. Acesso em: 15 mar. 2013.

LUKKA, K. The Constructive Research Approach. In: OJAL, L.; HILMOLA, O-P. (Eds.). Case Study Research in Logistics. Publications of the Turku School of Economics and Business Administration, 2003. Series B1.

LOSTUVALI, B.; ALVES, T. C. L.; MODRICH, R. Lean Product Development at Cathedral Hill Hospital Project. In: Annual conference of the International Group for Lean Construction, 20, 2012, San Diego. Proceedings... San Diego, v. 1, p. 1041-1050, jul. 2012.

MARCH, S.T.; SMITH, G.F. Design and natural science research on information technology. Decision Support Systems, v15, n.4, p.251-266, 1995. http://dx.doi.org/10.1016/0167-9236(94)00041-2

MACOMBER, H.; HOWELL, G.; BARBERIO, J. Target-Value Design: Nine Foundational Practices for Delivering Surprising Client Value. The American Institute of Architects, Practice Management Digest, winter, 2007.

MORAIS, M.; GRANJA, A. D.; RUSCHEL, R. C. Restrições orçamentárias e entrega de valor: sinergias entre BIM e custeio-meta. Gestão e Tecnologia de Projetos, São Paulo, v. 10, n. 1, p., jan./jun. 2015. http://dx.doi.org.br/10.11606/gtp.v10i1.81141

MORAIS, M. de. Método de implementação de BIM e custeio-meta em Habitação de Interesse Social. 2016. 336 f. Tese (Doutorado) - Faculdade de Engenharia Civil, Arquitetura e Urbanismo, Universidade Estadual de Campinas, Campinas, 2016.

RYBKOWSKI, Z. K. et al. Development and testing of a lean simulation to illustrate key principles of target value design: A first run study. In: Annual conference of the International Group for Lean Construction, 24, 2016, Proceedings... Boston, v. 1, p. 133-142, jul. 2016.

SACKS, R.; RADOSAVLJEVIC, M.; BARAK, R. Requirements for building information modeling based lean production management systems for construction. Automation in Construction, v. 19, n. 5, p. 641-655, 2010., August 2010. Acesso em: 18/8/2012.

SAVE. Save International. Disponível em:< http://www.value-eng.org/.> Acesso em : 10/11/2012.

TIWARI, S.; ODELSON, J; WATT, A.; KHANZODE, A.. Model Based Estimating to Inform Target Value Design. AECbytes, August 2009. Disponível em: <http://www.aecbytes.com/buildingthefuture/2009/ModelBasedEstimating to Inform Target Value Design> . Acesso em: 05 jun 2012.

\section{NOTAS}

${ }^{1}$ Os subsídios para a adaptação e criação do ferramental e o modelo teórico utilizaram como referência a Tese de Doutorado "Método para Implementação de BIM e custeio-meta em Habitação de Interesse Social" (MORAIS, 2016). A adaptação do ferramental ao novo contexto foi realizada ao longo da pesquisa de pós-doutorado desenvolvida no Instituto de Arquitetura e Urbanismo da Universidade de São Paulo (IAU-USP).

NOTA DO EDITOR (*) O conteúdo do artigo e as imagens nele publicadas são de responsabilidade do(s) autor(es). 


\section{ANEXOS}

Planilhas com as Ferramentas utilizadas para Gerenciamento de Valor, Dados a partir do projeto real da Unidade Básica de Saúde (UBS)

Anexo 1: Planilha Análise Funcional

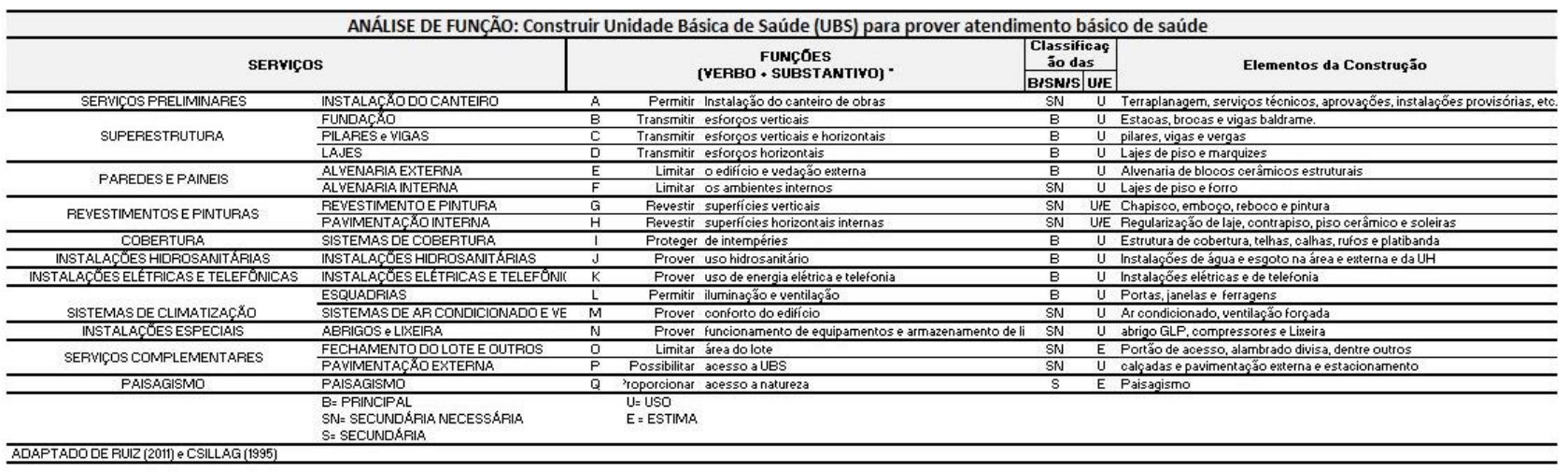

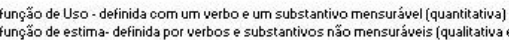

Fonte: Autores (2017)

\section{Anexo 2: Planilha contendo o consumo de recursos (custos $x$ funções)}

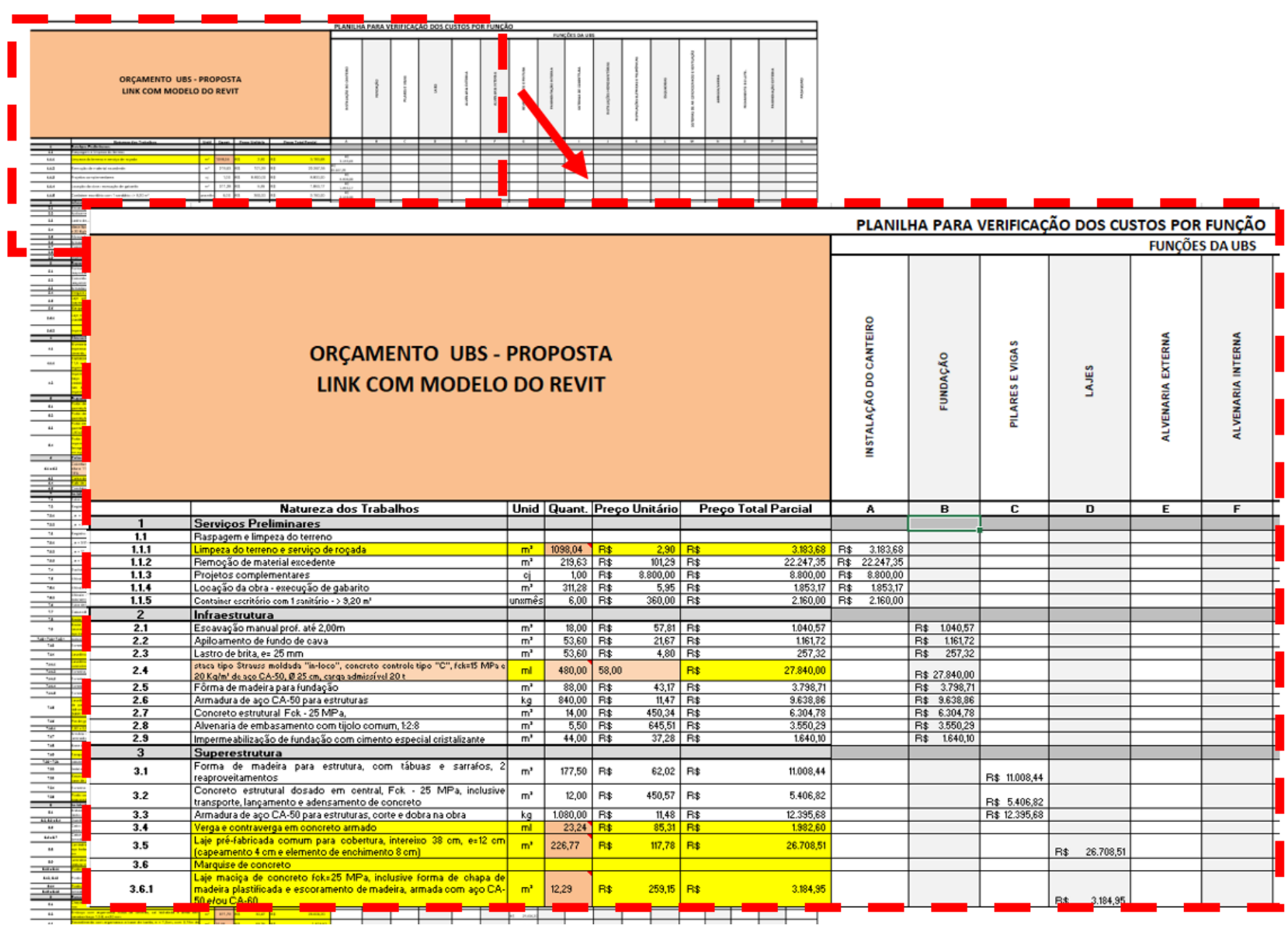

Fonte: Autores (2017) 
Anexo 3: Técnica de Mudge: planilha contendo as necessidades relativas dos usuários, comparação das funções par a par.
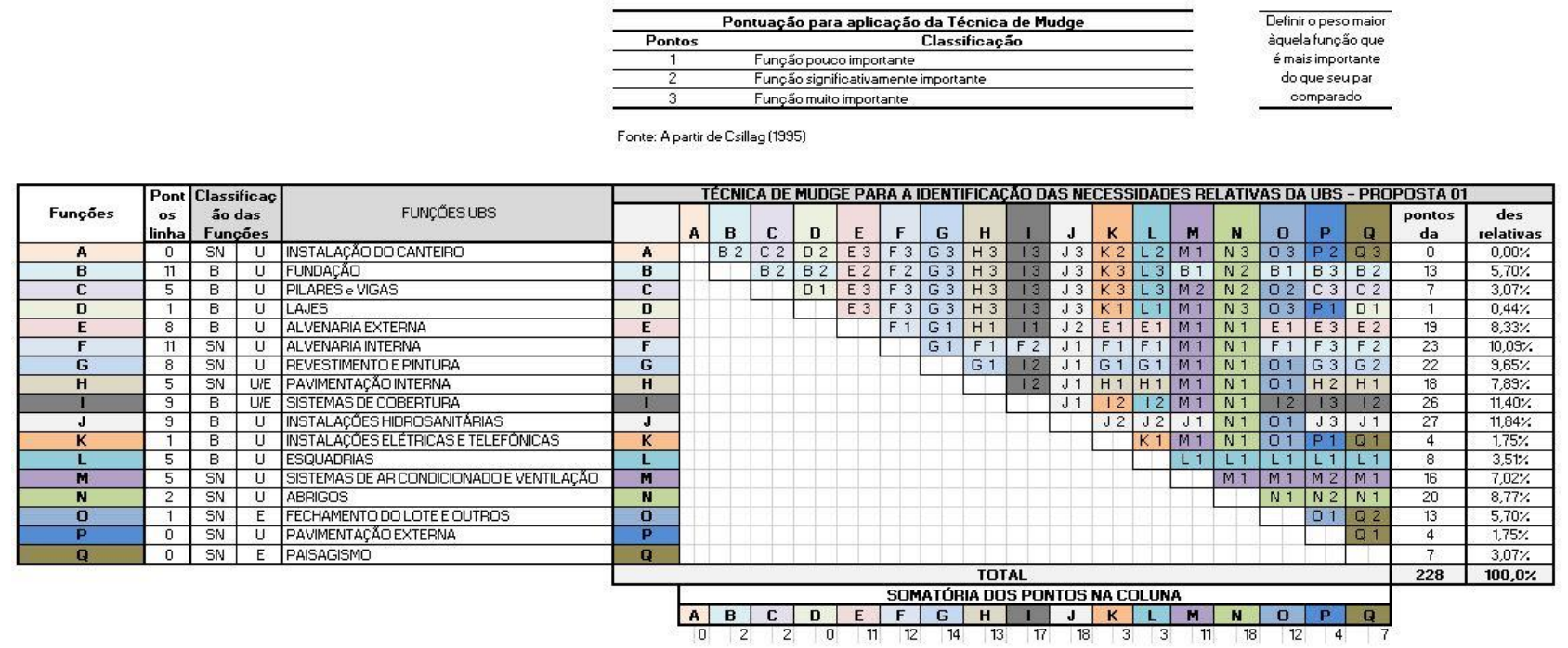

Fonte: Autores (2017)

Anexo 4: Gráfico Compare: Planilha comparando o consumo de recursos com as necessidades relativas (Técnica de Mudge)

\begin{tabular}{|c|c|c|c|c|c|c|c|c|}
\hline \multicolumn{9}{|c|}{ GRÁFICO COMPARE : CONSUMO DE RECURSOS X NECESSIDADE RELATIVA } \\
\hline \multicolumn{2}{|c|}{ SERVIÇOS } & & $\begin{array}{c}\text { FUNÇOES } \\
\text { (VERBO + SUBSTANTIVO] - }\end{array}$ & $\begin{array}{l}\text { CUSTO META } \\
\text { INICIAL. } \\
\text { (Rः) }\end{array}$ & $\begin{array}{l}\text { Consumo de } \\
\text { Recursos } \\
\text { INICIAL (\%) }\end{array}$ & $\begin{array}{c}\text { CUSTO } \\
\text { PROPOSTA }\end{array}$ & $\begin{array}{c}\text { Consumo de } \\
\text { Recursos } \\
\text { PROPOSTA } \\
\text { (\%) }\end{array}$ & $\begin{array}{c}\begin{array}{c}\text { Necessida } \\
\text { des } \\
\text { Relativas } \\
\text { (\%) }\end{array} \\
\end{array}$ \\
\hline SERVICCOSPRELIMINARES & INSTALACX̊ODOCANTEIRO & A & Permitir Instalaçẫo do canteiro de obras & $40.346,38$ & $7,6 \%$ & $40.346,38$ & $7,6 \%$ & $0,00 \%$ \\
\hline \multirow{3}{*}{ SUPERESTRUTURA } & FUNDAÇAOAO & B & Transmitit esforços verticais & $55.232,35$ & $10,4 \%$ & $55.232,35$ & $10,4 \%$ & $5,70 \%$ \\
\hline & PILARES E VIGAS & $\mathrm{C}$ & Transmitir esforços verticais e horizontais & $28.810,94$ & $5.4 \%$ & $28.810,94$ & $5,4 \%$ & $3,07 \%$ \\
\hline & LA.JES & $\mathrm{D}$ & Transmitit esforços horizontais & $30.827,50$ & $5,8 \%$ & $30.827,50$ & $5.8 \%$ & $0,44 \%$ \\
\hline \multirow{2}{*}{ PAREDESEPAINEIS } & ALVENARIAAEXTERNA & $E$ & Limitar oedifício e vedaçẫo externa & $23.073,31$ & $4,4 \%$ & $23.073,40$ & $4,4 \%$ & $8,33 \%$ \\
\hline & ALVENARIAINTERRA & $\mathrm{F}$ & Limitar os ambientes internos & $16.424,07$ & $3,1 \%$ & $16.424,16$ & $3, \%$ & $10,09 \%$ \\
\hline \multirow{2}{*}{ REVESTIMENTOSE PINTURAS } & REVESTIMENTOE PINTURA & $G$ & Revestit superficies verticais & $77.442,21$ & $14,6 \%$ & $77.442,21$ & $14,6 \%$ & $9,65 \%$ \\
\hline & PAVIMENTACCKOIINTERRA & $\mathrm{H}$ & Revestir superficies horizontais internas & $39.734,68$ & $7,5 \%$ & $39.734,68$ & $7,5 \%$ & $7,89 \%$ \\
\hline COBERTURA & SISTEMASDE COBERTURA & I & Proteger de intempéries & $33.570,29$ & $6,3 \%$ & $33.570,29$ & $6,3 \%$ & $11,40 \%$ \\
\hline INSTALACCOCES HIDROSANITÁRIASS & INSTALACCOES HIIDROSANITÁRIASS & J & Prover uso hidrosanitário & $50.484,19$ & $9.5 \%$ & $50.484,27$ & $9.5 \%$ & $11,84 \%$ \\
\hline \multirow{2}{*}{ INSTALACCOESELÉTRICASE TELEFONICAS } & INSTALACCOESELÉTTIICASE TELEFONIC & $\mathrm{K}$ & Prover uso de energia elétrica a telefonia & 49.278 .85 & $9,3 \%$ & $49.278,85$ & $9,3 \%$ & $1,75 \%$ \\
\hline & ESQUUADFIAS & $\mathrm{L}$ & Permitir iluminação e ventilaçăo & $36.022,16$ & $6,8 \%$ & $36.022,16$ & $6.8 \%$ & $3,51 \%$ \\
\hline SISTEMASDE CLIMATIZAC_ÁO & SISTEMASDE ARCONDICIONADOE VER & $M$ & Prover conforto do edifício & $4.584,72$ & $0,9 \%$ & $4.584,72$ & $0,9 \%$ & $7,02 \%$ \\
\hline INSTALAC,OESSESPECIAIS & ABRIIGOSELIXEIRA & $\mathrm{N}$ & Prover funcionamento de equipamentos. & $11.119,76$ & $2, \%$ & $11.119,76$ & $2, \%$ & $8,77 \%$ \\
\hline \multirow{2}{*}{ SERVIÇOS COMPLEMENTARES } & FECHAMENTODOLOTEEOUTROS & 므 & Limitar área dolote & $18.334,80$ & $3.5 \%$ & $18.334,80$ & $3,5 \%$ & $5,70 \%$ \\
\hline & PAVIMENTACROEXXTERNA & $\mathrm{P}$ & Possibilitar acesso aUBS & $9.413,49$ & $1,8 \%$ & $9.413,49$ & $1,8 \%$ & $1,75 \%$ \\
\hline \multirow[t]{2}{*}{ PAISAGISMO } & PAISAGISMO & Q & Proporcionar acesso a natureza & $4.025,38$ & $0.8 \%$ & $4.025,38$ & $0.8 \%$ & $3,07 \%$ \\
\hline & & & $\begin{array}{l}\text { TOTAIS } \\
\end{array}$ & $528.725,09$ & $100,0 \%$ & $528.725,34$ & $100,0 \%$ & $100,0 \%$ \\
\hline
\end{tabular}

Fonte: Autores (2017)

\section{Anexo 5: Gráfico Compare - Custo Meta Inicial x Proposta}

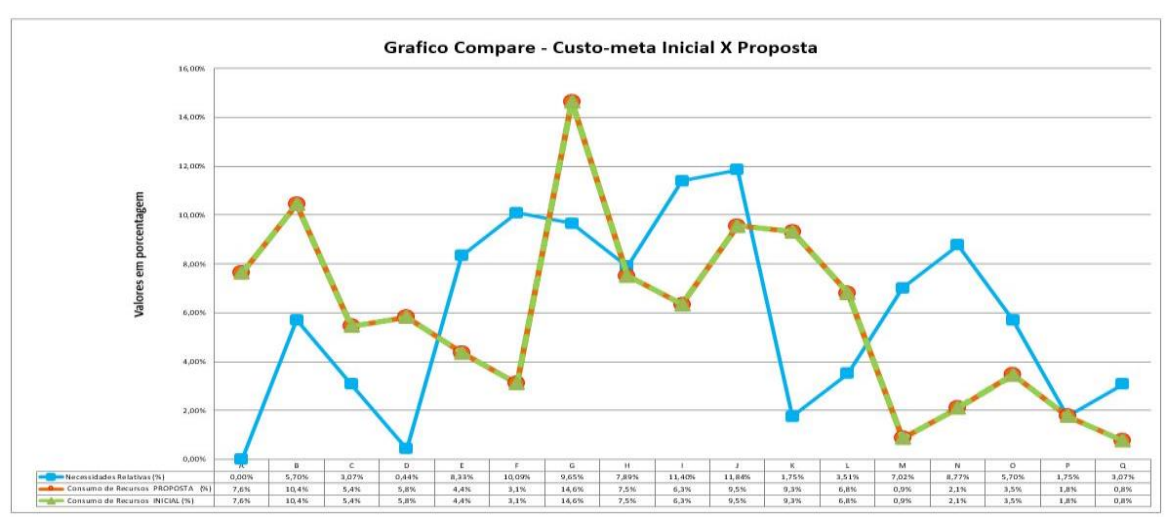

Fonte: Autores (2017) 